\title{
The Urokinase Plasminogen Activator System in Human Cancers: An Overview of Its Prognostic and Predictive Role
}

\author{
Josip Madunić ${ }^{1}$ \\ ${ }^{1}$ Division of Molecular Biology, Department of Biology, Faculty of \\ Science, University of Zagreb, Zagreb, Croatia \\ Thromb Haemost 2018;118:2020-2036.
}

\begin{abstract}
Address for correspondence Josip Madunić, PhD, Division of Molecular Biology, Department of Biology, Faculty of Science, University of Zagreb, Horvatovac 102a, 10000 Zagreb, Croatia (e-mail: jmadunic.biol@pmf.hr).
\end{abstract}

\begin{abstract}
Keywords

- urokinase plasminogen activator

- extracellular matrix

- cancer biomarker

- metastasis

- oncotherapy

Urokinase plasminogen activator (uPA) system regulates extracellular matrix remodelling by activating ubiquitous protease plasmin in many important physiological processes. The system components include UPA, plasminogen activator inhibitors (PAIs) and uPA receptor (UPAR). Besides its role in physiological processes, uPA system is active in most tumour types where its aberrant regulation has been associated with the development of metastatic phenotype. In vitro and in vivo studies have shown that the over-expression of UPA, PAI- 1 and UPAR not only enhances tumour cell invasion capacity and metastasis, but also corresponds to a higher risk of disease correlating with traditional clinicopathological features which makes them potential prognostic biomarkers and therapeutic targets in a wide range of human malignancies. This review focuses on uPA system's prognostic and predictive role in several types of human cancers, summarizing its activities in cancer development and highlighting the importance of addressing all unanswered questions before bridging the gap between laboratory findings to clinic use of uPA system's components as cancer biomarkers.
\end{abstract}

\section{Introduction}

The urokinase plasminogen activator (UPA) system, active in most tumour types, is a system that controls extracellular matrix (ECM) degradation by activating the ubiquitous protease plasmin. ${ }^{1-5}$ The key components of uPA system (uPAS) are uPA, plasminogen activator inhibitor-1 and -2(PAI-1, PAI-2) and uPA-associated receptor (UPAR), all of which play an essential role in the remodelling of ECM following various physiological processes such as embryogenesis, wound healing and postlactation involvement of breast tissue. ${ }^{6-10}$ Plasminogen is cleaved and activated to plasmin by several proteases, but uPA, a highly specific and substrate-restricted extracellular serine protease, ${ }^{11,12}$ is the most important plasminogen activator. ${ }^{13}$ uPAS regulation is strict and cell-specific involving the regulation of proenzyme, its inhibitors and receptor on several levels; through controlled transcription of individual system

received

April 14, 2018

accepted after revision

September 12, 2018

elements, degradation of their messenger ribonucleic acid (mRNA) and translation into proteins. ${ }^{14-19}$ The amount of UPA is precisely regulated through its interaction with inhibitors and UPAR. When UPA binds to UPAR, its activity becomes localized on the cell surface. ${ }^{4}$ On the other hand, if it reacts with uPAR as UPA/PAI complex, the whole structure undergoes endocytosis. Such translocation is dependent on the interaction with specific endocytosis receptors, like low-density lipoprotein receptor-related protein-1 (LRP-1).5 After endocytosis, UPA/PAI complex is degraded, while the uPAR returns to the surface ( - Fig. 1). ${ }^{20-23}$ In addition to its plasminogen-activating role, uPAS also stimulates many downstream signalling pathways and the regulation of the entire system is cell-specific. ${ }^{22,24}$

Participation in cell signalling is achieved through binding of UPA to UPAR and subsequent interaction of that complex with other proteins. uPAR, consisting of three homologous domains (DI, DII and DIII), is located on the plasma membrane and acts as

(c) 2018 Georg Thieme Verlag KG Stuttgart · New York
DOI https://doi.org/ 10.1055/s-0038-1675399. ISSN 0340-6245. 


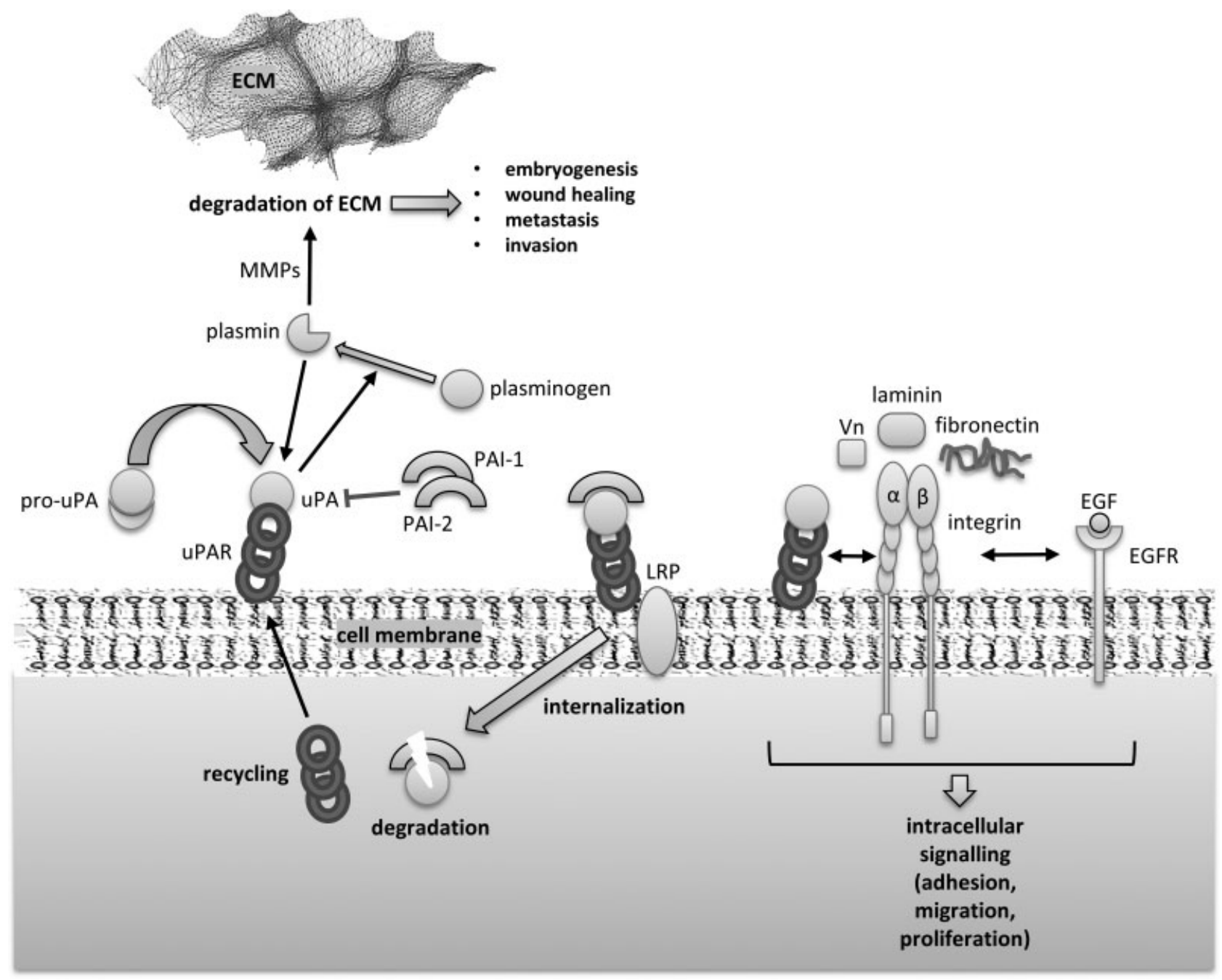

Fig. 1 The uPA system. The scheme of uPA system with its main components: uPA, inhibitors PAI-1, PAI-2 and receptor uPAR. Plasminogen is cleaved and activated to plasmin by uPA which facilitates ECM remodelling in important physiological processes as well as in pathological processes of cancer development. The amount of uPA is regulated through its interaction with inhibitors and uPAR. When uPA binds to uPAR, its activity is localized on the cell surface. In contrast, interaction of UPA/PAI complex with uPAR and proteins like LRP causes the whole structure to internalize and degrade while uPAR recycles. Association of UPAR with its interacting partners mediates intracellular signal transduction in processes of cell proliferation, adhesion, migration and survival (see the "Introduction" section for detailed description). ECM, extracellular matrix; EGF, epidermal growth factor; LRP, low-density lipoprotein receptor-related protein; MMPs, matrix metalloproteinases; PAI-1, plasminogen activator inhibitor; uPA, urokinase plasminogen activator; uPAR, urokinase plasminogen activator receptor; $V \mathrm{n}$, vitronectin.

a signalling receptor, but due to a lack of transmembrane and intracellular domains, it is unable to directly mediate intracellular signalling without interacting with other proteins. ${ }^{11}$ Its interacting partners are not limited to uPA but include membrane proteins like certain integrins (i.e. $\beta 1, \beta 2$ and $\beta 3$ ), $G$ protein-coupled chemotaxis receptors, LRP, caveolin, insulinlike growth factor receptor (IGFR), epidermal growth factor receptor (EGFR), platelet-derived growth factor receptor and other receptor tyrosine kinases, as well as ECM components like vitronectin $(\mathrm{Vn})$, fibronectin and collagen. $9,12,25,26$

Integrins are $\alpha \beta$-heterodimeric transmembrane receptors which connect ECM components to cytoskeletal proteins. They are responsible for cell-ECM adhesion and have been shown to be an important signalling co-receptors of uPAR. ${ }^{24}$ uPAR interacts with integrins through binding sites located on its two domains: DII and DIII. UPAR's ability to regulate integrin activity is crucial for the processes of cell prolifera- tion, adhesion, migration and survival ${ }^{23,27}$ ( - Fig. 1). Studies have shown that UPAR exhibits a strong affinity for $\alpha 5 \beta 1$ (fibronectin receptor), $\alpha 3 \beta 1$ (laminin receptor) and for $\alpha v \beta 5$ and $\alpha v \beta 3$ (Vn receptors) integrins when it is bound to uPA due to stabilization of its active conformation. ${ }^{22,27,28}$ Association of uPAR with $\alpha 5 \beta 1$ integrin induces cell growth by recruiting EGFR and activating extracellular signal-regulated kinases (ERKs). ${ }^{5}$ Moreover, integrins steer uPAR signalling: interaction with $\beta 1$ integrins triggers proliferation by activating focal adhesion kinase (FAK) and ERK, while the UPARB3 complex activates Rac Rho GTPase and induces cell migration. $\mathrm{Vn}$ is an adhesive ECM protein which is another important ligand for uPAR. In its multimeric conformation, it is able to interact with other proteins of ECM and integrin receptors. It has a different uPAR-binding site than uPA which enables UPAR to simultaneously interact with both, uPA and $\mathrm{Vn}^{29}$ 
Furthermore, the components of uPAS have been found to be over-expressed in cancer cells and the surrounding tissue, ${ }^{30,31}$ where their aberrant regulation is associated with metastatic capacity and poor clinical outcome. ${ }^{4,9,25}$ The process of cancer metastasis corresponds to the growth of a tumour at a site not adjacent to the primary tumour. To acquire invasive and metastatic properties, tumour cells have to pass through cellular and ECM barrier. ${ }^{28,32}$ An initial step that precedes this is local invasion consisting of extensive degradation of ECM (proteins like fibronectin) surrounding the tumour, which allows tumour cells to detach from an original site, enter blood or lymph circulation and spread to other organs or tissues in the body. ${ }^{33-35}$ Many studies have reported that tumour cells secrete increased levels of several proteolytic enzymes which facilitate tumour invasion and metastasis. ${ }^{36}$ Among those enzymes, uPA and matrix metalloproteinases (MMPs) are the most essential proteases in proteolytic cleavage of ECM. ${ }^{37,38}$

Surprisingly and contradictory to its uPA-inhibiting function, PAI-1, a serine proteinase, has been shown to positively regulate tumour development by promoting cell migration, enhancing angiogenesis and enabling apoptosis evasion in certain tumour types. ${ }^{11,29}$ uPAR signalling activities are regulated by PAI-1, which is another uPAS component capable of interacting with $\mathrm{Vn}$ and integrins. ${ }^{5,23,39}$ It has been shown that PAI-1 interferes with $\alpha 5 \beta 3$ integrin-Vn interaction which attenuates cell migration. Binding of PAI-1 to $\mathrm{Vn}$ can also contribute to the metastasis of cancer cells by blocking the uPAR- and integrin-dependent attachment of cells to Vn, which detaches cells from ECM. ${ }^{40}$ Interestingly, in a complex with uPA, PAI-1 loses the affinity for $\mathrm{Vn}$ and migration inhibitory action. ${ }^{41}$ Furthermore, the interaction of $\mathrm{Vn}$ and PAI-1 maintains inhibitor's active state. ${ }^{5}$ Studies have also observed elevated UPAR expression following the processes of inflammation and tumour growth. Some authors even suggest that tumour cells assimilate uPAR signalling to further their metastatic potential. Upon uPA binding, full-length uPAR is cleaved and shed from cell membrane, releasing its soluble forms (suPAR), which are also considered to be cancer biomarkers. ${ }^{42}$ Many studies have shown that cells in the invasive fronts of several cancer types exhibit over-expressed uPA and uPAR. In vivo and in vitro studies have demonstrated the importance of uPAS in both proteolytic and non-proteolytic processes during cancer development such as tumour cell proliferation, adhesion and migration, intravasation and extravasation, metastasis and neo-angiogenic growth. 1,30,43

Clinically relevant cancer biomarkers are invaluable in improving patient's outcome and in selecting an appropriate therapy. To be applicable in clinical medicine, biomarker has to meet certain requirements (for more details, see reviews ${ }^{11,40}$ ). A prognostic biomarker is a biological or clinical characteristic which informs about patient's outcome (prognosis), in the absence of any therapy. ${ }^{44}$ In contrast, predictive biomarker is able to predict a difference in benefit from a specific therapeutic intervention. ${ }^{45,46}$ The prognostic importance of uPAS was first suggested by Duffy et al in $1988,{ }^{47}$ when the authors showed that UPA activity in breast cancer correlated with tumour size and number of axillary nodes with metastases. Afterwards, additional studies have reported that besides uPA,
PAI-1 is also prognostically relevant, particularly in breast cancer patients. $^{39,40}$ Determination of both factors, uPA/PAI-1 (both low vs. high uPA and/or PAI-1), has been proved to be superior to assessing a single factor or using conventional prognostic markers for patient risk-group stratification. ${ }^{48}$ Various retrospective and prospective studies, including multicentric clinical trials (Chemo $\mathrm{N0}{ }^{10,49}$ and NNBC- $3^{9,50}$ ) and pooled meta-analyses, ${ }^{51}$ have since validated the prognostic and predictive value of UPA and PAI- 1 at the highest level of evidence (LOE- $1^{11}$ ) in breast cancer ${ }^{4,9,23}$ (for a summary of clinical milestones see Schmitt et $\mathrm{al}^{49}$ ). Interestingly, unlike any other cancer biomarker, there are no contradictions regarding the prognostic relevance of UPA/PAI-1 in breast cancer. ${ }^{23,39}$ Furthermore, predictive information obtained from uPA/PAI1 status can support individualized therapy selection and is being recommended and used routinely for treatment decision, particularly in node-negative breast cancer. ${ }^{10,39,52}$

From the available literature, it is evident that most of the research on the clinical relevance of UPA and PAI- 1 has been performed in breast cancer. ${ }^{49}$ Nowadays, uPAS is considered as a potential prognostic and predictive factor in many different human cancers (-Table 1), including those of breast, lung, bladder, stomach, intestine, uterus, kidney, thyroid, head and soft tissue (previously reviewed by Ulisse et $\mathrm{al}^{3}$ and Schmitt et $\mathrm{al}^{40}$ ). The aim of this article is to present an overview of recent research focusing on the role of uPAS in the development of human cancers.

\section{Methods}

The PubMed (www.ncbi.nlm.nih.gov/pubmed) database was searched on 13 November 2017 for all articles published in English in the past 10 years using the search term "cancer" AND "(uPA OR urokinase)" and applying filter Search Field "Title." Resulting 272 articles were afterwards methodically filtered in the next 3 weeks based on their relevance, redundancy in data, publication in respected journals and after reading them all and focusing on the ones reporting of uPAS activities in cancer development-reduced to 144 articles reviewed here in this article.

\section{The Role of uPA System in Cancer Invasion and Metastasis}

\section{Breast Cancer}

As mentioned previously, it was in breast cancer where the relationship between uPAS and tumourigenesis and metastasis was first proposed. ${ }^{47}$ The authors have studied the connection between uPA in primary breast carcinomas and different prognostic parameters and found that uPA activity was associated with the stage of disease and axillary node metastasis status. Also, primary carcinoma patients with observed high levels of uPA activity had much shorter disease-free survival (DFS) than the ones with low uPA activity. Furthermore, by performing (multivariable) analyses, previous clinical studies revealed that, aside from lymph node status, uPA and PAI- 1 had the strongest independent prognostic effect on DFS and overall survival (OS). ${ }^{51,53}$ 
Table 1 Activities of uPA system components in human cancers

\begin{tabular}{|c|c|c|c|c|}
\hline Cancer type & uPA system component & Observed effect & Study type & References \\
\hline \multirow[t]{19}{*}{ Breast } & uPA, uPAR, PAI-1, -2 & $\begin{array}{l}\text { uPAS components correlate with traditional } \\
\text { prognostic factors in patients }\end{array}$ & In vivo & $56,61,62,64$ \\
\hline & uPA, PAl-1 & $\begin{array}{l}\text { uPA and PAI- } 1 \text { are independent prognostic markers } \\
\text { for DFS and OS }\end{array}$ & In vivo & $51,53,58$ \\
\hline & uPA, PAl-1 & $\begin{array}{l}\text { uPA and PAI- } 1 \text { are predictive factors used in therapy } \\
\text { decision }\end{array}$ & In vivo & $10,39,52,72$ \\
\hline & UPAR & $\begin{array}{l}\text { Splice variant uPAR-del } 4 / 5 \text { is an independent } \\
\text { prognostic marker for DFS, DMFS and OS }\end{array}$ & $\begin{array}{l}\text { In vitro/ } \\
\text { In vivo }\end{array}$ & $38,42,63$ \\
\hline & UPAR & $\begin{array}{l}\text { uPAR-del } 4 / 5 \text { over-expression reduces breast cancer } \\
\text { cell adhesion and invasion }\end{array}$ & $\begin{array}{l}\text { In vitro/ } \\
\text { In vivo }\end{array}$ & 28,66 \\
\hline & uPA, UPAR & $\begin{array}{l}\text { uPA down-regulation and uPAR signalling } \\
\text { inhibition reverse EMT }\end{array}$ & In vitro & 69 \\
\hline & UPAR & $\begin{array}{l}\text { uPAR signalling induces CSC-like properties in } \\
\text { breast cancer cells }\end{array}$ & $\begin{array}{l}\text { In vitro/ } \\
\text { In vivo }\end{array}$ & 70 \\
\hline & $u P A$ & $\begin{array}{l}\text { miRNAs target uPA and modulate invasion of } \\
\text { breast cancer cells }\end{array}$ & In vitro/In vivo & 78,79 \\
\hline & UPAR & $\begin{array}{l}\text { miR- } 221 \text { targets uPAR7b and up-regulates its } \\
\text { protein expression in breast cancer cells }\end{array}$ & In vitro & 80 \\
\hline & $u P A$ & $\begin{array}{l}\text { Reduction of uPA expression via NF-кB inactivation } \\
\text { inhibits invasion of cancer cells }\end{array}$ & In vitro & 81 \\
\hline & uPA, PAl-1 & $\begin{array}{l}\text { Active TGF- } \beta \text { signalling correlates with high } \\
\text { expression of uPA and PAI- } 1 \text { in cancer tissue }\end{array}$ & In vivo & 82 \\
\hline & uPA, PAl-1 & $\begin{array}{l}\text { UPA/PAI-1 prognostic value is primarily detected in } \\
\text { HER2-positive breast cancer patients }\end{array}$ & In vivo & 59 \\
\hline & uPA, PAl-1 & $\begin{array}{l}\text { PAl-1 expression determination improves the } \\
\text { prognostic value of tumour size in patients }\end{array}$ & In vivo & 60 \\
\hline & UPAR & $\begin{array}{l}\text { Cleaved uPAR is better biomarker than elevated } \\
\text { uPAR expression in breast cancer-bearing mice }\end{array}$ & In vivo & 65 \\
\hline & UPAR & $\begin{array}{l}\text { Interactions of uPAR with uPA and IGFR-1 stimulate } \\
\text { migration and invasion in cancer cells }\end{array}$ & In vitro & 26 \\
\hline & UPAR & $\begin{array}{l}\text { Cysteine-rich angiogenic inducer-61 interacts with } \\
\text { uPAR in breast cancer cell invasion }\end{array}$ & In vitro/In vivo & 25 \\
\hline & uPA & $\begin{array}{l}\text { Concurrent suppression of uPA and MMP-9 } \\
\text { down-regulates migratory capacity of cancer cells }\end{array}$ & In vitro/In vivo & 71 \\
\hline & UPAR & $\begin{array}{l}\text { Depletion of uPAR from cancer cell membranes } \\
\text { inhibits invasion and slows tumour growth }\end{array}$ & In vitro/In vivo & 67 \\
\hline & uPA, PAl-1 & $\begin{array}{l}\text { Inhibition of uPA activity accompanied with TGF- } \beta \\
\text { activation arrests cancer cell growth }\end{array}$ & In vitro & 83 \\
\hline \multirow[t]{7}{*}{ Prostate } & $u P A$ & $\begin{array}{l}\text { Demethylation-associated induction of uPA } \\
\text { contributes to development of prostate cancer }\end{array}$ & In vivo & 19 \\
\hline & uPA, uPAR, PAl-1, -2 & $\begin{array}{l}\text { uPAS components correlate with main prognostic } \\
\text { markers in prostate cancer patients }\end{array}$ & In vivo & $84,87,88$ \\
\hline & UPA, UPAR & $\begin{array}{l}\text { Suppression of uPA/uPAR inhibits prostate cancer } \\
\text { cell growth and migration }\end{array}$ & In vitro & 92 \\
\hline & UPAR & $\begin{array}{l}\text { Serum UPAR is associated with cancer } \\
\text { extra-prostatic extension in cancer patients }\end{array}$ & In vivo & 85 \\
\hline & UPAR & $\begin{array}{l}\text { Anti-uPAR antibody reduces cancer cell invasion } \\
\text { and decreases xenograft tumour volume }\end{array}$ & In vitro/In vivo & 93 \\
\hline & UPAR & $\begin{array}{l}\text { Intact and cleaved uPAR correlate with OS in } \\
\text { prostate cancer patients }\end{array}$ & In vivo & 86 \\
\hline & UPA, UPAR & $\begin{array}{l}\mathrm{uPA}^{-1-} \text { and } \mathrm{uPAR}^{-I-} \text { mice exhibit reduced } \\
\text { xenograft tumour development }\end{array}$ & In vivo & 91 \\
\hline
\end{tabular}


Table 1 (Continued)

\begin{tabular}{|c|c|c|c|c|}
\hline Cancer type & uPA system component & Observed effect & Study type & References \\
\hline & UPA, UPAR & $\begin{array}{l}\text { Protein kinases D2/3 induce cancer cell invasion via } \\
\text { p65 NF-kB-associated activation of uPA }\end{array}$ & In vitro & 35 \\
\hline & uPA, PAI-1 & $\begin{array}{l}\text { uPA/PAI ratio distinguishes prostate cancer and } \\
\text { benign prostatic hyperplasia }\end{array}$ & In vivo & 89 \\
\hline & UPA, UPAR & $\begin{array}{l}\text { Snail over-expression increases cancer cells } \\
\text { invasion through uPA and uPAR up-regulation }\end{array}$ & In vitro & 96 \\
\hline & uPA, PAI-1 & $\begin{array}{l}\text { Increased methylation of PAI-1 promoter leads to } \\
\text { an increased proteolysis in cancer cells }\end{array}$ & In vitro/In vivo & 90 \\
\hline & $u P A$ & $\begin{array}{l}\text { CFTR over-expression inhibits uPA through } \\
\text { miR-193b induction }\end{array}$ & In vitro/In vivo & 97 \\
\hline & $u P A$ & $\begin{array}{l}\text { ETV4 inactivation supresses uPA expression and } \\
\text { inhibits invasion of prostate cancer cells }\end{array}$ & In vitro & 94 \\
\hline & UPA & $\begin{array}{l}\text { Aspirin down-regulates uPA expression and } \\
\text { decreases cancer cell invasion through NF-kB }\end{array}$ & In vitro & 95 \\
\hline \multirow[t]{14}{*}{ Colorectal } & uPA, PAI-1 & $\begin{array}{l}\text { uPA and PAI- } 1 \text { levels are better prognostic factors } \\
\text { than commonly used CRC markers }\end{array}$ & In vivo & 36 \\
\hline & uPA, PAl-1 & $\begin{array}{l}\text { uPA and PAI- } 1 \text { prognostic value is different in colon } \\
\text { and rectal cancers }\end{array}$ & In vivo & 98 \\
\hline & UPAR & $\begin{array}{l}\text { suPAR forms are up-regulated in CRC patients and } \\
\text { correlate with CRC metastasis }\end{array}$ & In vivo & $100-102$ \\
\hline & UPAR & $\begin{array}{l}\text { uPAR antibody suppresses CRC cell migration and } \\
\text { reduces tumour growth in xenograft model }\end{array}$ & In vitro/In vivo & 109 \\
\hline & UPA, UPAR & $\begin{array}{l}\text { Lipopolysaccharide induces CRC cell invasion by } \\
\text { stimulating uPA and uPAR }\end{array}$ & In vitro & 32 \\
\hline & $u P A$ & $\begin{array}{l}\text { GATA6 induces CRC cell invasion through } \\
\text { Sp1-associated activation of uPA promoter }\end{array}$ & In vitro & 34 \\
\hline & UPA, UPAR & $\begin{array}{l}\text { uPA is predictive marker for MMR-proficient CRC } \\
\text { correlating with pT stage and OS }\end{array}$ & In vivo & 99 \\
\hline & uPA, PAl-1 & $\begin{array}{l}\text { uPA and PAI- } 1 \text { levels are associated with tumour } \\
\text { budding in colon cancer }\end{array}$ & In vivo & 111,112 \\
\hline & UPA & $\begin{array}{l}\text { Stromal cell-derived factor- } 1 \text { induces uPA via } \\
\text { different pathways in CRC cells }\end{array}$ & In vitro & 106 \\
\hline & $u P A, U P A R$ & uPAR mRNA levels correlate with CRC stage & In vivo & 103 \\
\hline & UPAR & $\begin{array}{l}\text { uPAR-positive macrophages are markers of poor } \\
\text { OS in CRC patients }\end{array}$ & In vivo & 104 \\
\hline & UPAR & $\begin{array}{l}\text { Inactivation of uPAR promotes TRAIL-mediated } \\
\text { apoptosis in colon cancer cells }\end{array}$ & In vitro & 107 \\
\hline & UPA & $\begin{array}{l}\text { uPA inhibition mediated by 3,3'-diindolylmethane } \\
\text { suppresses CRC cell invasion }\end{array}$ & In vitro & 108 \\
\hline & UPAR & $\begin{array}{l}\text { uPAR is differently expressed in epithelium and } \\
\text { stroma-related rectal cancer cells }\end{array}$ & In vivo & 105 \\
\hline \multirow[t]{5}{*}{ Gastric } & UPAR & $\begin{array}{l}\text { Elevated uPAR by lysophosphatidic acid induces } \\
\text { the invasiveness of AGS cancer cells }\end{array}$ & In vitro & 113 \\
\hline & UPAR & $\begin{array}{l}\text { Invasive cancer cells over-expressing uPAR are a } \\
\text { predictive factor for poor OS }\end{array}$ & In vivo & 117 \\
\hline & uPA, UPAR, PAI-1 & $\begin{array}{l}\text { Expression of uPAS correlates with peritoneal } \\
\text { metastasis in gastric cancer patients }\end{array}$ & In vivo & 118,119 \\
\hline & UPA & $\begin{array}{l}\text { Semaphorin 5A-mediated uPA increase enhances } \\
\text { the invasiveness of gastric cancer cells }\end{array}$ & In vitro & 116 \\
\hline & UPAR & $\begin{array}{l}\text { Cadmium induces migration and invasion of AGS } \\
\text { gastric cancer cells by up-regulating UPAR }\end{array}$ & In vitro & 114 \\
\hline
\end{tabular}


Table 1 (Continued)

\begin{tabular}{|c|c|c|c|c|}
\hline Cancer type & uPA system component & Observed effect & Study type & References \\
\hline & $u P A$ & $\begin{array}{l}\text { uPA together with VEGF expression possesses a } \\
\text { prognostic value in invasive gastric cancer }\end{array}$ & In vivo & 120 \\
\hline & $u P A$ & $\begin{array}{l}\text { Elevated uPA is linked to gastric cancer stage and } \\
\text { negatively correlates with OS }\end{array}$ & In vivo & 121 \\
\hline & UPA & $\begin{array}{l}\text { uPA in cancer-associated fibroblasts stimulates } \\
\text { migration of oesophageal carcinoma cells }\end{array}$ & In vitro/In vivo & 122 \\
\hline & $U P A R$ & $\begin{array}{l}\text { Prostaglandin } E_{2} \text { increases gastric cancer cell } \\
\text { invasiveness by up-regulating uPAR expression }\end{array}$ & In vitro & 115 \\
\hline & $u P A, U P A R$ & $\begin{array}{l}\text { Quercetin suppresses cancer cells migration by } \\
\text { inhibiting UPA and uPAR expression }\end{array}$ & In vitro/In vivo & 123 \\
\hline \multirow[t]{7}{*}{ Ovarian } & UPAR & $\begin{array}{l}\text { Cleaved uPAR forms are differentiating factors } \\
\text { between benign and malignant ovarian cancer }\end{array}$ & In vivo & 128 \\
\hline & UPA, UPAR & $\begin{array}{l}\text { UPA and uPAR are over-expressed in cancer cells } \\
\text { and correlate with other prognostic factors }\end{array}$ & In vitro/In vivo & 130 \\
\hline & $u P A$ & $\begin{array}{l}\text { Co-expression of uPA and MDR-1 correlates with } \\
\text { the invasion of ovarian cancer }\end{array}$ & In vitro/In vivo & 131 \\
\hline & $u P A$ & $\begin{array}{l}\text { Basic fibroblast growth factor stimulates cancer } \\
\text { cell progression by up-regulating uPA expression }\end{array}$ & In vitro & 124 \\
\hline & $U P A R$ & $\begin{array}{l}\text { UPAR inhibition supresses the invasion of cancer } \\
\text { cells and reduces xenograft tumour development }\end{array}$ & In vitro/In vivo & 125 \\
\hline & uPA, PAl-1 & $\begin{array}{l}\text { uPA and PAI- } 1 \text { levels are higher in malignant than in } \\
\text { benign ovarian cancers }\end{array}$ & In vitro/In vivo & 126 \\
\hline & UPA & $\begin{array}{l}\text { Leptin-mediated uPA over-expression contributes } \\
\text { to ovarian cancer cell migration and invasion }\end{array}$ & In vitro & 127 \\
\hline \multirow[t]{5}{*}{ Lung } & $U P A R$ & $\begin{array}{l}\text { Intact and cleaved forms of uPAR are significant } \\
\text { prognostic factors in lung cancer patients }\end{array}$ & In vivo & $132-134$ \\
\hline & $u P A$ & $\begin{array}{l}\text { uPA expression is crucial for invasion induction in } \\
\text { A549 lung cancer cells by peroxiredoxin-6 }\end{array}$ & In vitro & 135 \\
\hline & uPA, UPAR & $\begin{array}{l}\text { UPA and uPAR SNPs have a prognostic value for the } \\
\text { predisposition and stage of NSCLC }\end{array}$ & In vivo & 138 \\
\hline & $u P A$ & $\begin{array}{l}\text { Kappa elastin induces lung cancer cell invasion by } \\
\text { stimulating uPA secretion }\end{array}$ & In vitro & 136 \\
\hline & UPA, UPAR & $\begin{array}{l}\text { NHE- } 1 \text { plays a crucial role in uPA/UPAR-mediated } \\
\text { metastasis of NSCLC cells }\end{array}$ & In vitro/In vivo & 137 \\
\hline \multirow[t]{6}{*}{ Pancreas } & UPAR & $\begin{array}{l}\text { Hypoxia-activated HIF induces uPAR, enabling } \\
\text { angiogenesis and invasion of cancer cells }\end{array}$ & In vitro/In vivo & 139 \\
\hline & UPA, UPAR & $\begin{array}{l}\text { uPA and uPAR suppression weakens metastatic } \\
\text { capacity of pancreatic cancer cells }\end{array}$ & In vitro/In vivo & 140 \\
\hline & uPA, PAl-1, uPAR & $\begin{array}{l}\text { PARK-7 controls pancreatic cancer cell invasiveness } \\
\text { through uPAS }\end{array}$ & In vitro/In vivo & 143 \\
\hline & uPA & $\begin{array}{l}\text { uPA induces stem-like characteristics to pancreatic } \\
\text { cancer cells }\end{array}$ & In vitro/In vivo & 141 \\
\hline & uPA & $\begin{array}{l}\text { Polyserase- } 1 \text { enhances PaCC invasion by } \\
\text { stimulating active uPA conversion }\end{array}$ & In vitro & 142 \\
\hline & UPAR & $\begin{array}{l}\text { UPAR expression correlates with OS in pancreatic } \\
\text { adenocarcinoma patients }\end{array}$ & In vivo & 144 \\
\hline
\end{tabular}

Abbreviations: CFTR, cystic fibrosis transmembrane conductance regulator; CRC, colorectal cancer; CSC, cancer stem cells; DFS, disease-free survival; DMFS, distant metastasis-free survival; EMT, epithelial-mesenchymal transition; HER2, human epidermal growth factor receptor 2; HIF, hypoxia-inducible factor; IGFR, insulin-like growth factor receptor; MAPK, mitogen-activated protein kinase; MDR-1, multiple drug-resistance-1; miRNA, micro ribonucleic acid; MMP, matrix metalloproteinase; MMR, mismatch repair; mRNA, messenger ribonucleic acid; NF-kB, nuclear factor kappa B; NHE-1, sodium hydrogen exchanger isoform-1; NSCLC, non-small cell lung cancer; OS, overall survival; PaCC, pancreatic cancer cells; PAl, plasminogen activator inhibitor; PARK-7, Parkinson's disease-associated protein-7; PI3K, phosphatidyl-inositol-3 kinase; SNP, single-nucleotide polymorphism; suPAR, soluble urokinase plasminogen activator receptor; TGF- $\beta$, transforming growth factor- $\beta$; TRAIL, tumour necrosis factor-related apoptosis-inducing ligand; uPA, urokinase plasminogen activator; UPAR, urokinase plasminogen activator receptor; UPAS, urokinase plasminogen activator system; VEGF, vascular endothelial growth factor. 
A particularly aggressive type of breast cancer cells are socalled triple-negative breast cancer (TNBC) cells, ${ }^{50}$ which do not express oestrogen and progesterone receptors or human EGFR 2 (HER2), making them unsusceptible to targeted therapy. ${ }^{54,55}$ Studies have shown that uPAS components were overexpressed in this sub-class of breast cancer cells. ${ }^{56}$ Metastatic breast cancer cells, such as TNBC MDA MB-231, are known to express higher levels of UPA and UPAR at cell surface enabling them to bind and activate larger amount of plasminogen. ${ }^{57} \mathrm{~A}$ study by Stillfried et $\mathrm{al}^{13}$ confirmed uPA as a crucial facilitator of breast cancer progression. The authors analysed plasminogen binding and activation at the surface of two breast cancer cell lines: MDA MB-231 and MCF-7, which differed in UPAR/uPA expression. Their results revealed that plasmin activity promoted plasminogen binding on the surface of breast cancer cells and was reliant on the presence of active uPA. Moreover, it was shown that increased uPA expression on the surface of metastatic breast cancer cells, such as MDA MB-231, upregulated plasmin activation which in turn enhanced their invasive proteolytic capacity.

After the long-term follow-up of lymph node-negative (LNN) breast cancer patients, Zemzoum et $\mathrm{al}^{58}$ have shown that uPA/PAI-1 levels were significantly associated with tumour aggressiveness, independently of HER2 status which was evaluated as well. Among conventional biomarkers, uPA/ PAI-1 status has been reported to be the only independent prognostic factor for DFS in uni- and multivariate analyses. Regarding the OS, a significant effect of both uPA/PAI-1 and HER2 status has been observed suggesting the complementary clinical use of both factors. In another study, Witzel et a ${ }^{59}$ evaluated the prognostic value of UPA and PAI-1 mRNA levels in molecular sub-types of breast cancer. The authors have observed a discrepancy in the prognostic role of UPA/PAI-1 mRNA in different sub-types. A meaningful prognostic value was primarily detected in patients with HER2-positive cancers, where the (uni- and multivariate) analysis showed a strong prognostic association between elevated uPA/PAI- 1 and shorter DFS. Similarly, a recent study suggested that PAI-1 expression determination can improve the prognostic value of tumour size in post-menopausal, LNN breast cancer patients and thus differentiate patients with low- and high-risk of disease recurrence during an early follow-up. ${ }^{60}$ Furthermore, a survey of 606 primary breast cancer patients established that the patients with high UPA and PAI-1 expression had larger tumours, of higher malignancy grade, capable of ductal invasion, but hormone-independent. ${ }^{61}$ Authors also observed that there was no substantial correlation between UPA and age or menopausal status. In another study, according to both uniand multivariate DFS analyses, same group demonstrated that uPA/PAI-1 expression represented independent prognostic value irrespective of HER2 status in LNN breast cancer patients during the long follow-up period of 8 years. ${ }^{62}$

Various forms of UPAR, differently cleaved or having diverse splicing, have been reported previously. ${ }^{1,3}$ By using univariate analysis, Luther et $\mathrm{al}^{42}$ discovered a significant association between higher expression of novel uPAR splice variant, uPAR-del $4 / 5$ (lacking exons 4 and 5) and shorter DFS in breast cancer patients. At the same time, wild-type UPAR
mRNA did not show such association with DFS which suggested a novel prognostic role of uPAR-del $4 / 5$ variant. These results were confirmed in a larger cohort of breast cancer patients using both uni- and multivariate analyses which showed that high UPAR-del $4 / 5$ level was an independent marker for shorter DFS. ${ }^{38}$ Additionally, low expression of tissue inhibitor of MMP-3 (TIMP-3) was significantly associated with similar poor prognosis. By combining these two independent prognostic factors, authors showed that patients with both high uPAR-del4/5 and low TIMP-3 had significantly shorter DFS compared with other patient subgroups. Another multivariate analysis revealed that the expression of uPAR-del4/5 and associated gene rab31 (Ras oncogene family) had a significant and independent prognostic impact on prognosis of untreated LNN breast cancer patients. ${ }^{63}$ Concurrent analysis of both factors showed that patients with high levels of uPAR-del $4 / 5$ and rab31 mRNA exhibited the worst distant metastasis-free survival (DMFS) and OS. In another study, an assessment of the role of uPAS in women with primary breast cancer revealed that the levels of UPAR were significantly higher in breast cancer patients, with positive correlation with other prognostic factors such as the stage of disease and the size of the primary tumor. ${ }^{64}$ Interestingly, the cleavage of uPAR has been recognized as a more specific cancer biomarker than the elevated expression of intact uPAR in breast cancer-bearing mice. ${ }^{65}$ Cleaved uPAR forms exhibited a significant correlation to tumour volume and were not affected by the depletion of UPA indicating the presence of another UPAR-cleaving proteases.

An in vitro study of MDA MB-231 TNBC transfected with uPAR-del4/5 showed that the over-expression of this receptor variant led to uPA-independent inhibition in cell adhesion and invasion. ${ }^{28}$ Moreover, an in vivo xenograft model demonstrated uPAR-del4/5-mediated suppression of breast cancer cell metastasis. Additional study by the same group demonstrated that the over-expression of uPAR-del $4 / 5$ diminished the invasive potential and adhesion of breast cancer cells in a dose-dependent manner. ${ }^{66}$ As these effects were contrary to the activity of endogenous receptor, it has been suggested that uPAR-del4/5 could, by competition, adversely regulate wild-type uPAR activity. Aside from its over-expression, interactions of UPAR with UPA and IGFR-1 have also been reported to stimulate migration and invasion in TNBC cell lines. ${ }^{26}$ The observed effect was annulled when the UPAR and UPA were silenced. A recent study by van Veen et $\mathrm{al}^{67}$ investigated the mechanism of UPAR shedding from cell surface and identified a specific phospholipase, glycerophosphodiesterase-3 (GDE3), which was able to cleave and inactivate UPAR. Furthermore, over-expression of GDE3 exhausted UPAR levels on the membranes of MDA MB-231 breast cancer cells making them less invasive as evidenced by slower tumour development in mice xenograft model.

Epithelial-mesenchymal transition (EMT) is an important process in development but is also involved in cancer metastasis. ${ }^{29,68}$ Previous studies have reported of hypoxia-induced EMT in cancer cells via uPAR cell signalling activation. Induction of EMT was also observed in cancer cells over-expressing uPAR. A study by Jo et al $^{69}$ examined if uPAR could be targeted to 
reverse EMT in uPAR-over-expressing breast cancer cells. Their findings demonstrated reversal of EMT which was caused by down-regulation of endogenous uPA or through uPAR-activated cell signalling inhibition. The same research group suggested that the appearance of cancer stem cell (CSC)-like properties in breast cancer cells was connected to uPAR signalling. This was further confirmed by the development of mammospheres when uPAR was over-expressed in breast cancer cells. ${ }^{70} \mathrm{~A}$ study by Moirangthem et al ${ }^{71}$ observed that concurrent suppression of UPA and MMP-9 down-regulated migratory and invasive capacity of breast cancer cells followed with an increase in the expression of epithelial marker E-cadherin and downregulation of mesenchymal markers, Snail and vimentin. The observe change in EMT genes was reminiscent of the expression modulation taking place in the mesenchymal-epithelial transition. Same effect was detected in vivo as well; human invasive breast tumour tissues displayed high expression of UPA and MMP-9, while the expression of E-cadherin was lower.

On the subject of potential predictive relevance of UPAS, retrospective analyses on a large number of breast cancer patients (for several studied patients see Schmitt et $\mathrm{al}^{4}$ ) have shown that high uPA/PAI-1 antigen levels correlate with an increased response to adjuvant chemotherapy with regard to patient's outcome like DFS. ${ }^{9,48}$ Correspondingly, a study by Meijer-van Gelder et $\mathrm{al}^{72}$ demonstrated that UPA, uPAR and PAI-1 provided predictive information regarding the hormone treatment of oestrogen receptor-positive breast cancer. Elevated expression of uPAS components was associated with a reduced tamoxifen efficacy (univariate analysis), where their values predicted shorter progression-free survival (PFS) in hormonetreated patients. Furthermore, multivariable model showed that UPA was an independent and significant predictive factor for tamoxifen therapy benefit.

As the patients with low UPA and PAI- 1 are less likely to relapse and do not benefit from adjuvant therapy, such overtreatment could be avoided there, ${ }^{11,49,50}$ even in patients with intermediate risk of recurrence. ${ }^{52,73}$ Analysis of Chemo NO trial showed that, even after extended follow-up ( $\sim 10$ years), prognostic and predictive value of $\mathrm{UPA} / \mathrm{PAI}-1$ was still significant regarding long-term outcome; suggesting the omission of adjuvant chemotherapy in low-uPA/PAI-1 patients and indicating its necessity where needed. ${ }^{10} \mathrm{By}$ guiding clinicians to unnecessary chemotherapy avoidance, uPA/PAI-1 determination has been shown to significantly reduce costs in breast cancer health care. ${ }^{74}$ Furthermore, study by Marguet et $\mathrm{al}^{73}$ analysed this cost-effectiveness in more detail and elucidated that the use of uPA/PAI- 1 testing in guiding chemotherapy decision was not so certain when the age of (node-negative) breast cancer patients was taken into consideration.

In most of the clinical studies, enzyme-linked immunosorbent assay (ELISA) is the standard method for determining UPA/ PAI-1 antigen content in tumour tissues. ${ }^{4,5,9,10,39,48}$ As the method demands rather large amounts ( $\sim 300 \mathrm{mg}$ ) of fresh or fresh-frozen tissue, ${ }^{75,76}$ other ways of assessing the uPA/PAI-1 status have been explored. ${ }^{4}$ Biermann et $\mathrm{al}^{77}$ analysed the uPA and PAI-1 mRNA expression by quantitative reverse transcription polymerase chain reaction (qRT-PCR) as an alternative to ELISA. Their findings revealed that there was no significant correlation between the mRNA and antigen expression in breast cancer samples which challenges the use of qRT-PCR as a substitute for direct protein detection by ELISA assays. Regarding the ELISA sample quantity requirement, it has been shown that even small tumour samples (10-30 mg), obtained from preoperative core needle biopsies, give enough significant information about the uPA/PAI- 1 status for patient stratification. $^{75}$ To bypass some of the disadvantages of ELISA, many research have also tried to quantify uPA and PAI-1 from formalin-fixed and paraffin-embedded material, commonly used format for tissue storage. Malinowsky et al ${ }^{76}$ successfully extracted UPA and PAI-1 proteins from such samples and confirmed that their expression was comparable to that obtained with ELISA.

It has been reported that different microRNAs (miRNAs), whose abnormal expression has been associated with carcinogenesis, may directly target uPAS components. A research by Li et $\mathrm{al}^{78}$ described miR-193b acting as a negative posttranscriptional regulator of uPA, and by doing so, supressing invasion of breast cancer cells. Similarly, another study showed that not only miR-193b, but miR-193a and miR-181a also targeted uPA mRNA. ${ }^{79}$ In this study, authors observed that diminished miRNA processing led to the increase in uPA expression followed by the enhanced in vitro invasion of breast cancer cells. Furthermore, a decreased concentration of aforementioned miRNAs was detected in breast cancer cells-overexpressing uPA. Depletion of uPA levels attenuated miRNA knockdown-associated invasion in those cells. A study by Falkenberg et $\mathrm{al}^{80}$ reported that miR-221 directly targets uPAR7b (secreted splicing variant) and up-regulates its protein expression in TNBC cells, an association which could be exploited in future therapies for invasive breast cancer. Potential candidates for breast cancer-targeted therapy are also cysteine-rich angiogenic inducer-61 and the Y-box-binding protein-1, whose interaction with UPAR has been recently identified and associated with TNBC invasion and migration. ${ }^{25}$ Furthermore, multivariate analysis revealed Y-box-binding protein- 1 as an independent prognostic factor for DMFS.

The promoter region of uPA contains the binding site for nuclear factor kappa $\mathrm{B}(\mathrm{NF}-\mathrm{kB})^{2,37}$ and constitutive activation of RelA, $\mathrm{p} 65$ sub-unit of NF-KB, is responsible for the over-expression of uPA in tumours. ${ }^{14} \mathrm{~A}$ study by Zong et al ${ }^{81}$ demonstrated that curcumin inhibited invasion of MCF-7 breast cancer cells by reducing uPA expression mediated through NF-кB inactivation. Another signalling pathway associated with uPAS and breast cancer is transforming growth factor- $\beta$ (TGF- $\beta$ ) pathway. A correlation study using tissue microarray technique in human breast cancer tissues discovered that almost all cancer samples had both active TGF- $\beta$ signalling and elevated uPA levels indicating a highly significant relationship between these two systems involved in breast cancer invasiveness. ${ }^{82}$ Another recent study demonstrated inhibition of the UPA activity in MDA MB-231 breast cancer cells which was associated with the TGF- $\beta$ pathway ${ }^{83}$ Treatment with non-steroidal anti-inflammatory drug sodium salicylate induced cellular reprogramming characterized by activation of TGF- $\beta$ pathway elements' and change in UPA/PAI-1 expression ratio which led to breast cancer cell growth arrest. 


\section{Prostate Cancer}

One of the most diagnosed cancers in men is prostate cancer, and according to statistics, it is a second most frequent cause of cancer-related death among men. Elevated expression of uPA has been found in prostate cancer cells, as well as in neighbouring stroma cells and metastatic lymph nodes. ${ }^{40}$ It has been reported that demethylation-associated induction of uPA expression played a role in the development and metastasis of prostate cancer. ${ }^{19}$ Human prostate cancer tissue samples exhibited abnormally expressed uPA which was not detected in adjacent tissue or benign prostatic hyperplasia (BPH). Furthermore, a study by Kumano et $\mathrm{al}^{84}$ showed that almost all uPAS components were associated with main prognostic markers in patients which had undergone radical prostatectomy. Expression of uPA, UPAR and PAI-1 strongly correlated with pathological stage, Gleason grading and lymph node metastasis. Additionally, multivariate analysis established that UPA expression provided independent prognostic information for DFS. ${ }^{84}$ Similarly, evaluation of serum UPAR and EGFR in patients suspected to have prostate cancer showed that the up-regulation of serum uPAR was associated with cancer extra-prostatic extension and could be used as a prognostic serum marker. ${ }^{85}$ Interestingly, serum levels of both intact and cleaved UPAR have been established to be good prognostic factors which correlated significantly in univariate analysis with OS of prostate cancer patients. Moreover, OS multivariate analysis identified uPAR(I-III) + uPAR(II-III) as an independent prognostic factor in androgen-blocked patients. ${ }^{86}$ Also, suPAR has been prognostically associated with shorter OS (in both uni- and multivariate analyses) in prostate cancer patients where high serum suPAR corresponded to multi-fold increase in death risk. ${ }^{87}$ The same authors broadened the research on SuPAR and included miR375 to analyse their combination as possible prostate cancer prognostic marker. ${ }^{88}$ Their uni- and multivariate survival analyses revealed a strong link between high suPAR/miR375 levels and poor OS in patients which suggests that a specific combination of miRNA and protein could be a valuable prognostic biomarker in prostate cancer. Another study has reported that PAI-1 protein concentrations were considerably higher than uPA concentrations in prostate cancer and $\mathrm{BPH}$ tissue sections. Since the resulting uPA/PAI-1 ratios were distinctly higher in prostate cancer samples, it was suggested that uPA/PAI ratio could be used as differentiating marker between prostate cancer and $\mathrm{BPH} .{ }^{89}$ Similarly, Hagelgans et $\mathrm{al}^{90}$ observed a change in the ratio of uPA/PAI-1 expression which corresponded to increased proteolysis in prostate cancer cells. One of the mechanisms behind such expression ratio shift was PAI-1 down-regulation due to increased methylation of its promoter, detected both in invasive prostate cancer cell lines (DU-145 and LNCaP) and prostate tumour samples.

Tumour-associated macrophages stimulate invasion, migration and metastasis in tumour microenvironment. As UPA and UPAR participate in macrophage chemotaxis, Zhang et $\mathrm{al}^{91}$ tested the link between uPA/uPAR and tumour-associated macrophages in prostate cancer. Their results revealed that RM-1 prostate cancer cell xenograft tumour development was significantly reduced in $\mathrm{uPA}^{-1-}$ and $\mathrm{uPAR}^{-1-}$ mice with fewer tumour-penetrating macrophages when compared with control mice. An in vitro study revealed that suppression of uPA and uPAR diminished cell growth and migration by inhibiting vascular endothelial growth factor (VEGF) and MMP-9 expression in prostate cancer cell lines. ${ }^{92}$ PC-3 prostate cancer cells incubated with monoclonal anti-uPAR antibody exhibited reduced invasion and migration due to the inactivation of FAK, Akt and mitogen-activated protein kinase (MAPK) signalling pathways. Moreover, treatment with uPAR antibody decreased tumour volume and attenuated skeletal lesions in in vivo models. ${ }^{93}$ In another study, PC-3 cells exhibited diminished migration and invasion caused by inhibited uPA expression due to the inactivation of Ets transcription factor ETV4. ${ }^{94}$

Constitutive activity of NF-KB pathway is one of the mechanisms behind prostate cancer metastasis. Protein kinases D2 and D3 were suggested to induce prostate cancer cell invasion via p65 NF-kB-associated activation of uPA. Suppression of kinases down-regulated uPA and uPAR levels and concurrently increased the expression of PAI-2. ${ }^{35}$ It has been recently shown that aspirin down-regulates uPA expression, which has led to a decrease in prostate cancer cell invasion. ${ }^{95}$ Detected decline in uPA expression was attributed to aspirin-mediated interference of NF-KB activation. In other study, prostate cancer cells transfected with EMT-inducing factor Snail exhibited increased invasion and migration which was a result of Snail-mediated up-regulation of UPA and UPAR levels. ${ }^{96}$ As reported previously in breast cancer cells, ${ }^{78}$ miRNA-193b targeted uPA and suppressed its expression. A study by Xie et al $^{97}$ discovered reduction in prostate tumour development associated with change in miR-193b-mediated modulation of uPA. Specifically, over-expression of ion channel protein cystic fibrosis transmembrane conductance regulator inhibited uPA expression via miR-193b induction in prostate cancer cell lines and xenograft tumours.

\section{Colorectal Cancer}

Colorectal cancer (CRC) is the most prevalent type of gastrointestinal cancer, affecting men and women equally. A high CRC-related mortality rate is the consequence of recurring metastases. So far, the most commonly used prognostic markers were carcinoembryonic antigen and the gastrointestinal cancer-associated carbohydrate antigen-19-9. Herszényi et $\mathrm{al}^{36}$ analysed blood samples from CRC patients and discovered that UPA and PAI-1 levels were better CRC prognostic factors than frequently used serum markers. In addition, PAI-1 contributed independent prognostic information in multivariate statistical analysis for OS. Interestingly, a study designed to analyse uPA and PAI-1 expression in large intestine cancers showed differing prognostic impact of these uPAS components in colon and rectal cancers; with UPA and PAI-1 being associated only with rectal cancer OS (univariate analyses), suggesting that their prognostic value was not generally relevant for all CRC types. ${ }^{98}$ Analysing two large CRC patient cohorts, characterized by their mismatch repair (MMR) status, Minoo et al $^{99}$ found, by using univariate and multivariable model, that uPA was an independent prognostic marker applicable particularly for MMR-proficient CRC where its up-regulation correlated with tumour stage, invasive margin and OS. 
Previous studies have suggested that the amount of cleaved UPAR in tumours corresponds to the activity of UPA and represents a better prognostic value than intact uPAR form. Similar to findings of studies in breast $\mathrm{t}^{42,65,67}$ and prostate cancers, ${ }^{86,87}$ various suPAR forms have been shown to be upregulated in CRC patients and to correlate with colorectal carcinogenesis. ${ }^{100}$ Additional study by the same group confirmed that all three suPAR types, suPAR(I-III), suPAR(II-III) and uPAR $(I)$, were independent markers of patient's OS and were more effective CRC prognostic markers as individual forms when compared with their sum, as demonstrated by uni- and multivariable analyses. ${ }^{101}$ Recently, the same authors reported that soluble intact and cleaved uPAR (suPAR(I-III) + (II-III)) was a valuable independent prognostic and predictive factor for metastatic CRC, which correlated well with patients' OS, as shown by uni- and multivariate analyses. ${ }^{102}$ Low level suPAR patients responded better to conventional chemotherapy than the ones with high suPAR concentrations. A research of Bujanda et al ${ }^{103}$ also showed that uPAR was a valuable CRC prognostic factor since its mRNA levels in blood correlated with and accurately diagnosed early-stage CRC. In another study, uni- and multivariate analyses showed that the number of high expressing uPAR macrophages, found in tumour centre, was significantly associated with poor OS of CRC patients. ${ }^{104}$ Expression of uPAR in epithelium ( $\mathrm{UPAR}^{\mathrm{E}}$ ) and stroma-related $\left(\mathrm{UPAR}^{\mathrm{S}}\right.$ ) rectal cancer cells was reported to be dissimilar suggesting different roles of UPAR in those two cell types. ${ }^{105}$ The authors discovered, by using multivariable model, significant and independent correlation between elevated $\mathrm{UPAR}^{\mathrm{E}}$ and poor OS in patients with non-metastatic rectal cancer. Contrastingly, $\mathrm{UPAR}^{\mathrm{S}}$ was prognostically associated with better $\mathrm{OS}$ in nodal-metastatic rectal cancer patients.

An in vitro study discovered that the transcription factor GATA6 induced CRC cell migration and invasion by enhancing uPA expression through Sp1-associated activation of UPA promoter. ${ }^{34}$ Similarly, it was reported that stromal cell-derived factor- 1 induced uPA expression and secretion by stimulating Sp1 and AP-1 binding on uPA promoter in DLD-1, SW48 and COLO205 CRC cell lines. ${ }^{106}$ Moreover, observed uPA up-regulation was connected to the activation of p38-MAPK and phosphatidyl-inositol-3 kinase (PI3K)/Akt pathways. Another study has reported that uPAR inactivation altered the expression of Bcl-2, Bax, Bid and p53 which promoted tumour necrosis factor-related apoptosis-inducing ligand-mediated apoptosis in HCT116 colon cancer cells. ${ }^{107} \mathrm{~A}$ recent study by Jin et al ${ }^{108}$ observed a decline in CRC cell invasion and migration, a consequence of UPA and MMP-9 inhibition caused by 3,3'-diindolylmethane.

In another study, treatment with uPAR monoclonal antibody ATN-658 suppressed CRC cell migration and invasion in vitro and caused a significant inhibition of tumour growth in the liver of CRC cell-xenograft model. ${ }^{109}$ Bacterial endotoxin lipopolysaccharide has been shown to induce CRC cell invasion by stimulating UPA and UPAR expression in vitro. ${ }^{32}$ Observed uPAS activation and subsequent increase in cell migration was attributed to lipopolysaccharide-mediated up-regulation of Toll-like receptor-4 and NF-KB. Tumour budding is a process occurring in some colorectal tumours when tumour cells disengage from the invasive tumour front as single cells or small clusters (up to five cells), to infiltrate blood vessels and establish metastases. ${ }^{110} \mathrm{~A}$ study by Märkl et $\mathrm{al}^{111}$ observed a significant association between uPA expression and tumour budding in colon cancer. In a recent study, the same research group provided a follow-up of colon cancer patients who were analysed in previous study. ${ }^{112}$ Their findings confirmed that uPA and PAI-1 were adverse predictive factors in colon cancer. Contrastingly to previous studies, they observed uPA to have lesser prognostic value than PAI-1, which, according to uni- and multivariate analyses, in tandem with tumour budding correlated independently with distant metastases in patients.

\section{Gastric Cancer}

Previous studies have shown an association between uPAS components over-expression and gastric cancer invasion (for an overview of earlier studies see Schmitt et $\mathrm{al}^{40}$ ). A study by Kim et a ${ }^{113}$ reported that elevated uPAR expression by lysophosphatidic acid treatment induced invasive capacity of AGS gastric cancer cells. UPAR levels were amplified through NF-кB and AP-1 signalling. Similarly, the same group reported that cadmium had up-regulated uPAR expression by activating AP-1, NF-KB and ERK-1/2 pathways and by doing so induced migration and invasion of AGS cells. ${ }^{114}$ Furthermore, gastric cancer cells exposed to prostaglandin $\mathrm{E}_{2}$ exhibited increased invasion due to the up-regulation of uPAR, mediated through EGFR-MAPK-NFкB and EGFR-MAPK-AP-1 pathways. ${ }^{115}$ In another study, over-expression of semaphorin 5A enhanced AGS cells invasiveness by activating PI3K/Akt signalling and inducing uPA expression. ${ }^{116}$

A study designed to evaluate the prognostic significance of uPAR in gastric cancer found that the presence of invasive gastric cancer cells over-expressing UPAR was a prognostic factor for poor OS, independent of usual prognostic parameters, as shown by uni- and multivariate analysis. ${ }^{117}$ In another study, expression of uPAS components was shown to be associated with peritoneal metastasis in gastric cancer patients. ${ }^{118}$ Using peritoneal implantation rat models and gastric cancer cell lines, the same authors have recently confirmed the connection between uPAS and gastric cancer metastasis. ${ }^{119}$ High uPA expression was found to correlate with high VEGF expression in gastric cancer tissue suggesting that the combination of these two factors could be used as a prognostic tool for invasive gastric cancer. ${ }^{120}$ Furthermore, analysis of peripheral blood from gastric adenocarcinoma patients revealed that elevated UPA expression was significantly linked to cancer stage and was negatively correlated with OS in univariate survival analysis. ${ }^{121} \mathrm{~A}$ recent study by Tian et al ${ }^{122}$ discovered elevated uPA expression in cancer-associated fibroblasts within the oesophageal squamous cell carcinoma tumours. Their findings showed that UPA concentration was inversely associated with patients' OS and was able to stimulate cancer cells migration and invasion in vitro. Also, quercetin has been recently shown to suppress the migratory ability of BGC823 and AGS gastric cancer cells by decreasing uPA and uPAR expression. ${ }^{23}$ 


\section{Ovarian Cancer}

High uPA and PAI-1 expression was found not only in ovarian cancer tissue, but also in adjacent cyst and ascitic fluids. ${ }^{40} \mathrm{An}$ in vitro study by Li and Jiang ${ }^{124}$ demonstrated that basic fibroblast growth factor stimulates the invasion of SKOV3 ovarian cancer cells by increasing uPA expression through transcription factor Ets-1. Administration of ATN-658 uPAR antibody supressed the invasion and migration in SKOV3ip1, HeyA8 and CaOV3 ovarian cancer cell lines and attenuated the development of xenograft tumours by inducing apoptosis and disrupting the uPAR-integrin interactions. ${ }^{125} \mathrm{~A}$ study by Zhang et al ${ }^{126}$ showed that the expression of uPA and PAI1 in malignant and non-differentiated ovarian cancers was much higher than in normal or benign ovarian tissue, with uPA expression being an independent prognostic factor as demonstrated by multivariate analysis. In the same study, over-expression of UPA increased the adhesion and metastatic capacity of SKOV3 cells. Also, it has been reported recently that uPA contributed to leptin-associated induction of ovarian cancer cell migration and invasion. ${ }^{127}$ Leptinstimulated uPA over-expression in OVCAR3 and SKOV3 cells was regulated through Rho/Rho-associated protein kinase, Janus kinase/Signal transducer and activator of transcription-3, PI3K/Akt and NF-KB signalling pathways.

Furthermore, a clinical study by Henic et al ${ }^{128}$ showed that cleaved UPAR forms possessed significant prognostic value in ovarian cancer patients, as demonstrated by univariate analysis. In a multivariate setting, high uPAR(I) concentration was an independent indicator of poor OS, while the combination of suPAR(I-III) + suPAR(II-III) with conventional ovarian cancer marker, cancer antigen-125, differentiated benign from invasive tumours. In contrast to their prognostic relevance in breast cancer, ${ }^{38,42,63}$ mRNA expression levels of wild-type uPAR, uPAR-del4/5 and rab31, albeit correlated among themselves, did not have any significant prognostic effect on PFS and OS of ovarian cancer patients. ${ }^{129}$ In another study, eight different ovarian cancer cell lines exhibited over-expressed uPA and UPAR. ${ }^{130}$ Similar over-expression was found in ovarian cancer samples and corresponding metastatic lesions, where it correlated with tumour grade, clinical stage, relapse time and PFS of patients. In the next study, same authors reported of coexpression of uPA with multiple drug-resistance-1 (MDR-1) marker in primary ovarian tumours and ovarian cancer cell lines. ${ }^{131}$ Observed up-regulation of uPA and MDR- 1 correlated with the expansion of ovarian cancer, suggesting that UPA interaction with drug resistance could be targeted to tackle resistant forms of metastatic ovarian cancer. Contrary to the findings in uPAS research, univariate model by Zhao et al ${ }^{12}$ recently demonstrated that high expression of plasminogen was associated with extended OS. A multivariable analysis confirmed that plasminogen was a statistically independent prognostic factor for OS in advanced ovarian cancer.

\section{Lung Cancer}

Interestingly, some of the previous studies in lung cancer have revealed that not uPA, but rather PAI-1 expression was related to patient's prognosis. ${ }^{40}$ Non-small cell lung cancer (NSCLC) is the most common type of lung cancer, characterized by insensitivity to chemotherapy and unfavourable prognosis. A clinical study by Almasi et al ${ }^{132}$ reported of the link between poor OS and intact and cleaved forms of UPAR from preoperatively sampled blood of 32 NSCLC patients. Next study, including more NSCLC patients, confirmed, in a univariate setting, that all uPAR forms were predictors of poor OS. ${ }^{133}$ In particular, multivariate OS model identified serum UPAR(I-III) and $\mathrm{UPAR}(\mathrm{I})$ as lung cancer prognostic factors, independent of the general parameters. Similarly, the authors have analysed soluble uPAR levels in small cell lung cancer patients. ${ }^{134}$ Their uni- and multivariate regression analyses showed that serum UPAR(I) concentration significantly and independently correlated with short patients' OS.

An in vitro study demonstrated that elevated uPA expression was crucial for invasion promotion in A549 lung cancer cells by peroxiredoxin-6, an effect which was mediated through PI3K/Akt signalling pathway. ${ }^{135}$ Lung ECM is rich in elastin which, upon degradation, forms peptides with biological activities. One of such elastin-derived peptides is kappa-elastin, capable of augmenting the invasiveness of lung cancer cells. The findings of Toupance et $\mathrm{al}^{136}$ revealed that the mechanism behind kappa-elastin-mediated induction of invasion was the stimulation of uPA secretion, observed only in invasive lung cancer cell lines.

In another study, Provost et $\mathrm{al}^{137}$ demonstrated that the activity of sodium hydrogen exchanger isoform-1 played a crucial role in UPA/uPAR-mediated metastasis of NSCLC cells, both in vitro and in vivo, indicating that $\mathrm{pH}$ alternation could impact cancer cell growth. Interestingly, a study by Shih et a ${ }^{138}$ showed that single-nucleotide polymorphisms in UPA and uPAR gene have a prognostic value when it comes to the predisposition and stage of NSCLC. The authors have associated uPA rs4065 TT genotype with higher susceptibility to lung cancer, while the patients with uPAR-344781 CC genotype were less probable to be diagnosed with lung cancer.

\section{Pancreatic Cancer}

Studies have shown that uPA expression is elevated in pancreatic cancer. It was found to be associated with survival and able to predict metastasis in pancreatic cancer patients. ${ }^{40}$ In one of the previous studies, authors have shown that hypoxic conditions and resulting activation of hypoxia-inducible factor induce uPAR expression, enabling in that way tumour angiogenesis and invasion of pancreatic cancer cells $(\mathrm{PaCC}) .{ }^{139} \mathrm{~A}$ study by Gorantla et al ${ }^{140}$ reported that suppression of uPA and UPAR strongly weakened metastatic capacity of MIA PaCa-2 and PANC-1 PaCC. This uPAS down-regulation also triggered cell cycle arrest, activated apoptosis and inhibited angiogenic factors in affected cancer cells. Additional study by the same group analysed the correlation between uPA and formation of CSC in pancreatic cancer. ${ }^{141}$ Their findings showed that UPA induced stem-like characteristics to MIA PaCa-2 and PANC-1 PaCC by interacting with specific homeobox transcription factors LIM/homeobox-2 and homeobox-A5. By inhibiting uPA expression, the authors were able to decrease tumorigenicity and chemoresistance of CSC-like PaCC. Furthermore, uPA suppression impaired the development of pancreatic tumours in vivo and diminished the expression of p53. Another 
in vitro study reported that serine protease polyserase-1 enhanced invasive and migratory capacity of PANC-1 PaCC by stimulating the conversion of pro-uPA to active uPA. ${ }^{142}$

Parkinson's disease-associated protein-7 (PARK-7) has been shown to control PaCC invasiveness through uPAS. ${ }^{143}$ The authors have suppressed PARK-7 expression in BxPC-3 and SW1990 PaCC and observed concomitant inhibition of cell invasion and metastasis, both in vitro and in vivo. These effects were related to reduced uPA activity which was also a result of PARK-7 knockdown. Recent immunohistochemical evaluation of 122 pancreatic adenocarcinoma patients discovered that more than $60 \%$ of patients expressed uPAR not only in tumour cells, but in surrounding stromal cells as well. ${ }^{144}$ Nevertheless, only tumour cell uPAR expression was significantly (reversely) correlated with patient's DFS and OS in multivariate model, implicating its independent clinical significance in discriminating patients with higher risk.

\section{Conclusion and Future Perspectives}

In this review, a summary of studies reporting on the roles and activities of uPAS components in various types of human cancers is presented. uPAS, consisting of UPA, PAIs and UPAR, regulates ECM remodelling by activating ubiquitous protease plasmin in many important physiological processes. Because of their significance, expression of uPAS components is controlled on several levels. Furthermore, they participate in pathological processes as well, where the de-regulation of their activity and expression promotes tumour development and metastasis. Even though PAI-1 is the main inhibitor of uPA's proteolytic activity, several studies demonstrate that this over-expression stimulates cell migration and tumour invasion. A reason for this contradiction is the fact that PAI-1 mediates signalling pathways independent of uPA inhibition. High PAI-1 expression has been reported to cause tumour cell detachment, which enables metastasis and invasion, to inhibit apoptosis and stimulate tumour cell proliferation.

UPAR is an integral component of uPAS which not only concentrates uPA's proteolytic activity at cell surface, but also acts as a receptor in signalling pathways which are not associated with uPA proteolysis. Elevated UPAR expression also correlates with aggressive cancer phenotype and precedes invasion and metastasis in almost all types of human cancers. Therefore, future efforts should focus on developing cancer therapies which target and/or inhibit uPAR and its interaction partners. Seeing as high UPAR expression is feature characteristic to cancer cells, such therapeutic targeting would have little or no effect on normal cells. Beside uPA, many other uPAR-binding ligands have been discovered suggesting alternative uPAR-targeting therapies in future studies. Given that most of the cell UPAR is bound to uPA, a relevant subject for future research would be the development of therapeutic drugs capable of targeting bound uPAR such as monoclonal anti-uPAR antibody ATN-658.

Despite numerous studies on the uPAS' role in tumour development, a few unanswered questions still remain. Tumour microenvironment with nearby stroma cells has been shown to play a role in tumour development. Studies reviewed here report of high uPAS components' expression in tumour stroma, which suggests possible inter-play between stroma and tumour cells, and even regulation of tumour progression by paracrine stroma signalling. Consequently, a better clarification of stroma cell's role in tumour development is needed to better understand their complex interaction. Moreover, modulation of uPAS expression might be used to control that interaction in new therapeutic approaches targeting the tumour stroma. At last, what should be also evaluated in the future is which uPA contributes more to tumour growth; host-derived or tumourderived? What complicates this discernment is that uPA and PAI-1, are also secreted by normal cells in physiological processes such as wound healing, developmental tissue remodelling, vessel growth and post-lactational mammary gland involution. Therefore, more specific drugs, targeting only tumour-associated uPAS components, are needed for more efficient therapies. One of the knowledge gaps in this field of research is the thorough identification and description of uPAS cellular interactions. It is necessary to elucidate the interaction of uPAS with other ECM-degrading proteases active in carcinogenesis, such as MMPs. Previous studies have observed that UPA and UPAR influence tumour development by interacting with integrins and growth factors. Even more, some authors suggest that uPAR-Vn interaction could be an attractive target for uPAS modulation in tumour progression and metastasis. CSCs, cancer cells with stem-like properties, have been found to influence metastasis and relapse of various types of both haematopoietic and solid tumours. Studies reviewed here show that UPA, PAI-1 and UPAR participate in the emergence of CSCs as well as in the induction of EMT, two processes which are associated with drug resistance and apoptosis evasion in cancer. However, further studies are needed to elucidate the exact contribution of uPAS components in maintaining cancer cell stemness and enabling chemoresistance. Additionally, in the future studies, an emphasis should be placed on in vivo models because tumour cell xenografts are not fully suitable due to incompatibility between human uPA and murine UPAR (or vice versa), which excludes any tumour-stroma interactions in UPAS.

An early diagnosis, in most types of cancer, is the only thing that might improve prognosis and positively affect OS in cancer patients. Sometimes, an absence of any strong symptoms conceals the disease until the patients are already in the advance stage, which complicates any further effective treatment. The clinical studies that are reviewed here have evaluated and confirmed the clinical utility of uPA and PAI-1, especially their role as reliable prognostic and predictive cancer markers. This is supported by the fact that uPA and PAI-1 have been declared as LOE-1 in breast cancer. Furthermore, both UPAR and its soluble forms have been shown to be efficient prognostic markers in distinguishing poor prognosis and predicting therapy response in cancer patients. Therefore, the determination of uPAS components could help with the pre-treatment screening of patients and their subsequent stratification in low- or high-risk group. That knowledge could help advance the individualization of oncotherapy, particularly in the terms of selecting the appropriate therapy and predicting its specific benefit. 
In summary, the assessment of the existing literature indicates that uPAS plays a clinically relevant role as a prognostic and predictive factor in several human malignancies. Over-expression of UPA, PAI- 1 and UPAR not only enhances tumour cell invasion capacity and metastasis, but also corresponds to a higher risk of disease and correlates with poor prognosis. Moreover, uPAS expression has been reported to be associated with common clinicopathological features such as pT stage, Gleason grading, lymph node metastasis, lymphovascular invasion and tumour size. It is important to note that, even though UPAS participates in a variety of physiological and pathological processes, it was not reported to be vital for cell proliferation and/or survival under normal physiological circumstances. Correspondingly, uPAS is emerging as an attractive target in novel therapeutic approaches for cancer treatment, but it is necessary to address all knowledge uncertainties before bridging the gap between laboratory findings to clinic use.

\section{Funding}

This work was supported by the University of Zagreb, Faculty of Science.

\section{Conflict of Interest}

None.

\section{Acknowledgements}

The author would like to thank Dr. Ivana Vrhovac Madunić for critical reading of the manuscript. Appreciative thanks are also extended to Prof. Maja Matulić for the introduction to the field of urokinase plasminogen activator system.

\section{References}

1 Irigoyen JP, Muñoz-Cánoves P, Montero L, Koziczak M, Nagamine Y. The plasminogen activator system: biology and regulation. Cell Mol Life Sci 1999;56(1-2):104-132

2 Nagamine Y, Medcalf RL, Muñoz-Cánoves P. Transcriptional and posttranscriptional regulation of the plasminogen activator system. Thromb Haemost 2005;93(04):661-675

3 Ulisse S, Baldini E, Sorrenti S, D’Armiento M. The urokinase plasminogen activator system: a target for anti-cancer therapy. Curr Cancer Drug Targets 2009;9(01):32-71

4 Schmitt M, Mengele K, Gkazepis A, et al. Assessment of urokinase-type plasminogen activator and its inhibitor PAI- 1 in breast cancer tissue: historical aspects and future prospects. Breast Care (Basel) 2008;3(s2):3-10

5 Mengele K, Napieralski R, Magdolen V, et al. Characteristics of the level-of-evidence-1 disease forecast cancer biomarkers uPA and its inhibitor PAI-1. Expert Rev Mol Diagn 2010;10(07):947-962

6 Solberg H, Ploug M, Høyer-Hansen G, Nielsen BS, Lund LR. The murine receptor for urokinase-type plasminogen activator is primarily expressed in tissues actively undergoing remodeling. J Histochem Cytochem 2001;49(02):237-246

7 Danø K, Behrendt N, Høyer-Hansen G, et al. Plasminogen activation and cancer. Thromb Haemost 2005;93(04):676-681

8 Lijnen HR. Pleiotropic functions of plasminogen activator inhibitor-1. J Thromb Haemost 2005;3(01):35-45

9 Annecke K, Schmitt M, Euler U, et al. uPA and PAI-1 in breast cancer: review of their clinical utility and current validation in the prospective NNBC-3 trial. Adv Clin Chem 2008;45:31-45
10 Harbeck N, Schmitt M, Meisner C, et al; Chemo-N O Study Group. Tenyear analysis of the prospective multicentre Chemo-NO trial validates American Society of Clinical Oncology (ASCO)-recommended biomarkers uPA and PAI- 1 for therapy decision making in node-negative breast cancer patients. Eur J Cancer 2013;49(08):1825-1835

11 Duffy MJ, McGowan PM, Harbeck N, Thomssen C, Schmitt M. uPA and PAI- 1 as biomarkers in breast cancer: validated for clinical use in level-of-evidence-1 studies. Breast Cancer Res 2014;16(04):428

12 Zhao S, Dorn J, Napieralski R, et al. Plasmin(ogen) serves as a favorable biomarker for prediction of survival in advanced highgrade serous ovarian cancer. Biol Chem 2017;398(07):765-773

13 Stillfried GE, Saunders DN, Ranson M. Plasminogen binding and activation at the breast cancer cell surface: the integral role of urokinase activity. Breast Cancer Res 2007;9(01):R14

14 Wang W, Abbruzzese JL, Evans DB, Chiao PJ. Overexpression of urokinase-type plasminogen activator in pancreatic adenocarcinoma is regulated by constitutively activated RelA. Oncogene 1999;18(32):4554-4563

15 Tran H, Maurer F, Nagamine Y. Stabilization of urokinase and urokinase receptor mRNAs by HuR is linked to its cytoplasmic accumulation induced by activated mitogen-activated protein kinase-activated protein kinase 2. Mol Cell Biol 2003;23(20): 7177-7188

16 Benasciutti E, Pagès G, Kenzior O, Folk W, Blasi F, Crippa MP. MAPK and JNK transduction pathways can phosphorylate Sp1 to activate the uPA minimal promoter element and endogenous gene transcription. Blood 2004;104(01):256-262

17 Hiendlmeyer E, Regus S, Wassermann S, et al. Beta-catenin upregulates the expression of the urokinase plasminogen activator in human colorectal tumors. Cancer Res 2004;64(04):1209-1214

18 Crippa MP. Urokinase-type plasminogen activator. Int J Biochem Cell Biol 2007;39(04):690-694

19 Pulukuri SMK, Estes N, Patel J, Rao JS. Demethylation-linked activation of urokinase plasminogen activator is involved in progression of prostate cancer. Cancer Res 2007;67(03):930-939

20 Plesner T, Behrendt N, Ploug M. Structure, function and expression on blood and bone marrow cells of the urokinase-type plasminogen activator receptor, uPAR. Stem Cells 1997;15(06):398-408

21 Aguirre Ghiso JA, Alonso DF, Farías EF, Gomez DE, de Kier Joffè EB. Deregulation of the signaling pathways controlling urokinase production. Its relationship with the invasive phenotype. Eur J Biochem 1999;263(02):295-304

22 Blasi F, Sidenius N. The urokinase receptor: focused cell surface proteolysis, cell adhesion and signaling. FEBS Lett 2010;584(09): 1923-1930

23 Harbeck N, Kates RE, Gauger K, et al. Urokinase-type plasminogen activator (UPA) and its inhibitor PAI-I: novel tumor-derived factors with a high prognostic and predictive impact in breast cancer. Thromb Haemost 2004;91(03):450-456

24 Smith HW, Marshall CJ. Regulation of cell signalling by uPAR. Nat Rev Mol Cell Biol 2010;11(01):23-36

25 Huber MC, Falkenberg N, Hauck SM, et al. Cyr61 and YB-1 are novel interacting partners of uPAR and elevate the malignancy of triplenegative breast cancer. Oncotarget 2016;7(28):44062-44075

26 Huber MC, Mall R, Braselmann H, et al. uPAR enhances malignant potential of triple-negative breast cancer by directly interacting with UPA and IGF1R. BMC Cancer 2016;16:615

27 Montuori N, Pesapane A, Rossi FW, et al. Urokinase type plasminogen activator receptor (UPAR) as a new therapeutic target in cancer. Transl Med UniSa 2016;15:15-21

28 Sato S, Kopitz C, Grismayer B, et al. Overexpression of the urokinase receptor mRNA splice variant uPAR-del $4 / 5$ affects tumor-associated processes of breast cancer cells in vitro and in vivo. Breast Cancer Res Treat 2011;127(03):649-657

29 Su S-C, Lin C-W, Yang W-E, Fan W-L, Yang S-F. The urokinase-type plasminogen activator (UPA) system as a biomarker and therapeutic target in human malignancies. Expert Opin Ther Targets 2016;20(05):551-566 
30 Duffy MJ. The urokinase plasminogen activator system: role in malignancy. Curr Pharm Des 2004;10(01):39-49

31 Dass K, Ahmad A, Azmi AS, Sarkar SH, Sarkar FH. Evolving role of UPA/uPAR system in human cancers. Cancer Treat Rev 2008;34 (02):122-136

32 Killeen SD, Wang JH, Andrews EJ, Redmond HP. Bacterial endotoxin enhances colorectal cancer cell adhesion and invasion through TLR4 and NF-kappaB-dependent activation of the urokinase plasminogen activator system. Br J Cancer 2009;100(10):1589-1602

33 Chou RH, Hsieh SC, Yu YL, Huang MH, Huang YC, Hsieh YH. Fisetin inhibits migration and invasion of human cervical cancer cells by down-regulating urokinase plasminogen activator expression through suppressing the p38 MAPK-dependent NF-кB signaling pathway. PLoS One 2013;8:1-12

34 Belaguli NS, Aftab M, Rigi M, Zhang M, Albo D, Berger DH. GATA6 promotes colon cancer cell invasion by regulating urokinase plasminogen activator gene expression. Neoplasia 2010;12(11): 856-865

35 Zou Z, Zeng F, Xu W, et al. PKD2 and PKD3 promote prostate cancer cell invasion by modulating NF-KB- and HDAC1-mediated expression and activation of uPA. J Cell Sci 2012;125(Pt 20):4800-4811

36 Herszényi L, Farinati F, Cardin R, et al. Tumor marker utility and prognostic relevance of cathepsin B, cathepsin L, urokinase-type plasminogen activator, plasminogen activator inhibitor type-1, CEA and CA 19-9 in colorectal cancer. BMC Cancer 2008;8:194

37 Hsieh M-J, Yeh C-B, Chiou H-L, Hsieh M-C, Yang S-F. Dioscorea nipponica attenuates migration and invasion by inhibition of urokinase-type plasminogen activator through involving PI3K/Akt and transcriptional inhibition of NF-[Formula: see text]B and SP-1 in hepatocellular carcinoma. Am J Chin Med 2016;44(01):177-195

38 Kotzsch M, Farthmann J, Meye A, et al. Prognostic relevance of uPAR-del4/5 and TIMP-3 mRNA expression levels in breast cancer. Eur J Cancer 2005;41(17):2760-2768

39 Harbeck N, Schmitt M, Paepke S, Allgayer H, Kates RE. Tumorassociated proteolytic factors UPA and PAI-1: critical appraisal of their clinical relevance in breast cancer and their integration into decision-support algorithms. Crit Rev Clin Lab Sci 2007;44(02): 179-201

40 Schmitt M, Mengele K, Napieralski R, et al. Clinical utility of levelof-evidence-1 disease forecast cancer biomarkers uPA and its inhibitor PAI-1. Expert Rev Mol Diagn 2010;10(08):1051-1067

41 Mekkawy AH, Pourgholami MH, Morris DL. Involvement of urokinase-type plasminogen activator system in cancer: an overview. Med Res Rev 2014;34(05):918-956

42 Luther T, Kotzsch M, Meye A, et al. Identification of a novel urokinase receptor splice variant and its prognostic relevance in breast cancer. Thromb Haemost 2003;89(04):705-717

43 Béné MC, Castoldi G, Knapp W, et al; EGIL, European Group on Immunological Classification of Leukemias. CD87 (urokinasetype plasminogen activator receptor), function and pathology in hematological disorders: a review. Leukemia 2004;18(03): 394-400

44 Oldenhuis CNAM, Oosting SF, Gietema JA, de Vries EGE. Prognostic versus predictive value of biomarkers in oncology. Eur J Cancer 2008;44(07):946-953

45 Clark GM. Prognostic factors versus predictive factors: examples from a clinical trial of erlotinib. Mol Oncol 2008;1(04):406-412

46 Ballman KV. Biomarker: predictive or prognostic? J Clin Oncol 2015;33(33):3968-3971

47 Duffy MJ, O'Grady P, Devaney D, O'Siorain L, Fennelly JJ, Lijnen HJ. Urokinase-plasminogen activator, a marker for aggressive breast carcinomas. Preliminary report. Cancer 1988;62(03):531-533

48 Harbeck N, Kates RE, Schmitt M, et al. Urokinase-type plasminogen activator and its inhibitor type 1 predict disease outcome and therapy response in primary breast cancer. Clin Breast Cancer 2004;5(05):348-352

49 Schmitt M, Harbeck N, Brünner N, et al. Cancer therapy trials employing level-of-evidence-1 disease forecast cancer biomar- kers uPA and its inhibitor PAI-1. Expert Rev Mol Diagn 2011;11 (06):617-634

50 Kantelhardt EJ, Vetter M, Schmidt M, et al. Prospective evaluation of prognostic factors $\mathrm{UPA} / \mathrm{PAI}-1$ in node-negative breast cancer: phase III NNBC3-Europe trial (AGO, GBG, EORTC-PBG) comparing $6 \times$ FEC versus $3 \times$ FEC/ $3 \times$ Docetaxel. BMC Cancer 2011;11:140

51 Look MP, van Putten WLJ, Duffy MJ, et al. Pooled analysis of prognostic impact of urokinase-type plasminogen activator and its inhibitor PAI-1 in 8377 breast cancer patients. J Natl Cancer Inst 2002;94(02):116-128

52 Kolben T, Augustin D, Armbrust R, et al. Impact of guideline-based use of uPA/PAI-1 on patient outcome in intermediate-risk early breast cancer. Breast Cancer Res Treat 2016;155(01):109-115

53 Look M, van Putten W, Duffy M, et al. Pooled analysis of prognostic impact of UPA and PAI-1 in breast cancer patients. Thromb Haemost 2003;90(03):538-548

54 Cleator S, Heller W, Coombes RC. Triple-negative breast cancer: therapeutic options. Lancet Oncol 2007;8(03):235-244

55 Hudis CA, Gianni L. Triple-negative breast cancer: an unmet medical need. Oncologist 2011;16(Suppl 1):1-11

56 Foekens JA, Peters HA, Look MP, et al. The urokinase system of plasminogen activation and prognosis in 2780 breast cancer patients. Cancer Res 2000;60(03):636-643

57 Ranson M, Andronicos NM, O'Mullane MJ, Baker MS. Increased plasminogen binding is associated with metastatic breast cancer cells: differential expression of plasminogen binding proteins. $\mathrm{Br}$ J Cancer 1998;77(10):1586-1597

58 Zemzoum I, Kates RE, Ross JS, et al. Invasion factors UPA/PAI-1 and HER2 status provide independent and complementary information on patient outcome in node-negative breast cancer. J Clin Oncol 2003;21(06):1022-1028

59 Witzel I, Milde-Langosch K, Schmidt M, et al. Role of urokinase plasminogen activator and plasminogen activator inhibitor mRNA expression as prognostic factors in molecular subtypes of breast cancer. Onco Targets Ther 2014;7:2205-2213

60 Buta M, Džodić R, Đurišić I, et al. Potential clinical relevance of UPA and PAI-1 levels in node-negative, postmenopausal breast cancer patients bearing histological grade II tumors with ER/PR expression, during an early follow-up. Tumour Biol 2015;36(10): 8193-8200

61 Lampelj M, Arko D, Cas-Sikosek N, et al. Urokinase plasminogen activator ( $\mathrm{UPA}$ ) and plasminogen activator inhibitor type-1 (PAI1 ) in breast cancer - correlation with traditional prognostic factors. Radiol Oncol 2015;49(04):357-364

62 Dovnik NF, Takac I. Prognostic significance of uPA/PAI-1 level, HER2 status, and traditional histologic factors for survival in node-negative breast cancer patients. Radiol Oncol 2016;51(01): $65-73$

63 Kotzsch M, Sieuwerts AM, Grosser M, et al. Urokinase receptor splice variant uPAR-del4/5-associated gene expression in breast cancer: identification of rab31 as an independent prognostic factor. Breast Cancer Res Treat 2008;111(02):229-240

64 Thielemann A, Baszczuk A, Kopczyński P, Kopczyński Z. High concentration of urokinase-type plasminogen activator receptor in the serum of women with primary breast cancer. Contemp Oncol (Pozn) 2013;17(05):440-445

65 Thurison T, Almholt K, Gårdsvoll H, Ploug M, Høyer-Hansen G, Lund IK. Urokinase receptor cleavage correlates with tumor volume in a transgenic mouse model of breast cancer. Mol Carcinog 2016;55(05):717-731

66 Grismayer B, Sato S, Kopitz C, et al. Overexpression of the urokinase receptor splice variant uPAR-del $4 / 5$ in breast cancer cells affects cell adhesion and invasion in a dose-dependent manner and modulates transcription of tumor-associated genes. Biol Chem 2012;393(12):1449-1455

67 van Veen M, Matas-Rico E, van de Wetering K, et al. Negative regulation of urokinase receptor activity by a GPI-specific phospholipase C in breast cancer cells. eLife 2017;6:1-20 
68 Thiery JP. Epithelial-mesenchymal transitions in tumour progression. Nat Rev Cancer 2002;2(06):442-454

69 Jo M, Lester RD, Montel V, Eastman B, Takimoto S, Gonias SL. Reversibility of epithelial-mesenchymal transition (EMT) induced in breast cancer cells by activation of urokinase receptor-dependent cell signaling. J Biol Chem 2009;284(34):22825-22833

70 Jo M, Eastman BM, Webb DL, Stoletov K, Klemke R, Gonias SL. Cell signaling by urokinase-type plasminogen activator receptor induces stem cell-like properties in breast cancer cells. Cancer Res 2010;70(21):8948-8958

71 Moirangthem A, Bondhopadhyay B, Mukherjee M, et al. Simultaneous knockdown of uPA and MMP9 can reduce breast cancer progression by increasing cell-cell adhesion and modulating EMT genes. Sci Rep 2016;6:21903

72 Meijer-van Gelder ME, Look MP, Peters HA, et al. Urokinase-type plasminogen activator system in breast cancer: association with tamoxifen therapy in recurrent disease. Cancer Res 2004;64(13): 4563-4568

73 Marguet S, Mazouni C, Ramaekers BLT, et al. European costeffectiveness study of uPA/PAI-1 biomarkers to guide adjuvant chemotherapy decisions in breast cancer. Eur J Cancer 2016; 63:168-179

74 Jacobs VR, Kates RE, Kantelhardt E, et al. Health economic impact of risk group selection according to ASCO-recommended biomarkers uPA/PAI-1 in node-negative primary breast cancer. Breast Cancer Res Treat 2013;138(03):839-850

75 Thomssen C, Harbeck N, Dittmer J, et al. Feasibility of measuring the prognostic factors uPA and PAI- 1 in core needle biopsy breast cancer specimens. J Natl Cancer Inst 2009;101(14):1028-1029

76 Malinowsky K, Böllner C, Hipp S, Berg D, Schmitt M, Becker KF. UPA and PAI- 1 analysis from fixed tissues - new perspectives for a known set of predictive markers. Curr Med Chem 2010;17(35): 4370-4377

77 Biermann JC, Holzscheiter L, Kotzsch M, et al. Quantitative RTPCR assays for the determination of urokinase-type plasminogen activator and plasminogen activator inhibitor type 1 mRNA in primary tumor tissue of breast cancer patients: comparison to antigen quantification by ELISA. Int J Mol Med 2008;21(02): 251-259

78 Li X-F, Yan P-J, Shao Z-M. Downregulation of miR-193b contributes to enhance urokinase-type plasminogen activator (uPA) expression and tumor progression and invasion in human breast cancer. Oncogene 2009;28(44):3937-3948

79 Noh H, Hong S, Dong Z, Pan ZK, Jing Q Huang S. Impaired microRNA processing facilitates breast cancer cell invasion by upregulating urokinase-type plasminogen activator expression. Genes Cancer 2011;2(02):140-150

80 Falkenberg N, Anastasov N, Schaub A, et al. Secreted UPAR isoform 2 (UPAR7b) is a novel direct target of miR-221. Oncotarget 2015;6(10):8103-8114

81 Zong H, Wang F, Fan QX, Wang LX. Curcumin inhibits metastatic progression of breast cancer cell through suppression of urokinase-type plasminogen activator by NF-kappa B signaling pathways. Mol Biol Rep 2012;39(04):4803-4808

82 Lang DS, Marwitz S, Heilenkötter U, et al. Transforming growth factor-beta signaling leads to uPA/PAI-1 activation and metastasis: a study on human breast cancer tissues. Pathol Oncol Res 2014;20(03):727-732

83 Madunić J, Horvat L, Majstorović I, Jodłowska I, Antica M, Matulić M. Sodium salicylate inhibits urokinase activity in MDA MB-231 breast cancer cells. Clin Breast Cancer 2017;17(08):629-637

84 Kumano M, Miyake H, Muramaki M, Furukawa J, Takenaka A, Fujisawa M. Expression of urokinase-type plasminogen activator system in prostate cancer: correlation with clinicopathological outcomes in patients undergoing radical prostatectomy. Urol Oncol 2009;27(02):180-186

85 Milanese G, Dellabella M, Fazioli F, et al. Increased urokinase-type plasminogen activator receptor and epidermal growth factor receptor in serum of patients with prostate cancer. J Urol 2009; 181(03):1393-1400

86 Almasi CE, Brasso K, Iversen P, et al. Prognostic and predictive value of intact and cleaved forms of the urokinase plasminogen activator receptor in metastatic prostate cancer. Prostate 2011; 71(08):899-907

87 Al-Janabi O, Taubert H, Lohse-Fischer A, et al. Association of tissue mRNA and serum antigen levels of members of the urokinase-type plasminogen activator system with clinical and prognostic parameters in prostate cancer. BioMed Res Int 2014; 2014:972587

88 Wach S, Al-Janabi O, Weigelt K, et al. The combined serum levels of miR-375 and urokinase plasminogen activator receptor are suggested as diagnostic and prognostic biomarkers in prostate cancer. Int J Cancer 2015;137(06):1406-1416

89 Böhm L, Serafin A, Akudugu J, Fernandez P, van der Merwe A, Aziz NA. uPA/PAI-1 ratios distinguish benign prostatic hyperplasia and prostate cancer. J Cancer Res Clin Oncol 2013;139(07):1221-1228

90 Hagelgans A, Menschikowski M, Fuessel S, et al. Deregulated expression of urokinase and its inhibitor type 1 in prostate cancer cells: role of epigenetic mechanisms. Exp Mol Pathol 2013;94(03):458-465

91 Zhang J, Sud S, Mizutani K, Gyetko MR, Pienta KJ. Activation of urokinase plasminogen activator and its receptor axis is essential for macrophage infiltration in a prostate cancer mouse model. Neoplasia 2011;13(01):23-30

92 Ahmad A, Kong D, Sarkar SH, Wang Z, Banerjee S, Sarkar FH. Inactivation of UPA and its receptor uPAR by 3,3'-diindolylmethane (DIM) leads to the inhibition of prostate cancer cell growth and migration. J Cell Biochem 2009;107(03):516-527

93 Rabbani SA, Ateeq B, Arakelian A, et al. An anti-urokinase plasminogen activator receptor antibody (ATN-658) blocks prostate cancer invasion, migration, growth, and experimental skeletal metastasis in vitro and in vivo. Neoplasia 2010;12(10):778-788

94 Qi M, Liu Z, Shen C, et al. Overexpression of ETV4 is associated with poor prognosis in prostate cancer: involvement of uPA/ uPAR and MMPs. Tumour Biol 2015;36(05):3565-3572

95 Shi C, Zhang N, Feng Y, Cao J, Chen X, Liu B. Aspirin inhibits IKK- $\beta$ mediated prostate cancer cell invasion by targeting matrix metalloproteinase- 9 and urokinase-type plasminogen activator. Cell Physiol Biochem 2017;41(04):1313-1324

96 Randle DD, Clarke S, Henderson V, Odero-Marah VA. Snail mediates invasion through uPA/uPAR and the MAPK signaling pathway in prostate cancer cells. Oncol Lett 2013;6(06):1767-1773

97 Xie C, Jiang XH, Zhang JT, et al. CFTR suppresses tumor progression through miR-193b targeting urokinase plasminogen activator (uPA) in prostate cancer. Oncogene 2013;32(18): 2282-2291, 2291.e1-2291.e7

98 Langenskiöld M, Holmdahl L, Angenete E, Falk P, Nordgren S, Ivarsson ML. Differential prognostic impact of UPA and PAI-1 in colon and rectal cancer. Tumour Biol 2009;30(04):210-220

99 Minoo P, Baker K, Baumhoer D, Terracciano L, Lugli A, Zlobec I. Urokinase-type plasminogen activator is a marker of aggressive phenotype and an independent prognostic factor in mismatch repair-proficient colorectal cancer. Hum Pathol 2010;41(01):70-78

100 Lomholt AF, Høyer-Hansen G, Nielsen HJ, Christensen IJ. Intact and cleaved forms of the urokinase receptor enhance discrimination of cancer from non-malignant conditions in patients presenting with symptoms related to colorectal cancer. Br J Cancer 2009;101(06):992-997

101 Lomholt AF, Christensen IJ, Høyer-Hansen G, Nielsen HJ. Prognostic value of intact and cleaved forms of the urokinase plasminogen activator receptor in a retrospective study of 518 colorectal cancer patients. Acta Oncol 2010;49(06):805-811

102 Tarpgaard LS, Christensen IJ, Høyer-Hansen G, et al. Intact and cleaved plasma soluble urokinase receptor in patients with metastatic colorectal cancer treated with oxaliplatin with or without cetuximab. Int J Cancer 2015;137(10):2470-2477 
103 Bujanda L, Sarasqueta C, Cosme A, et al. Evaluation of alpha 1antitrypsin and the levels of mRNA expression of matrix metalloproteinase 7 , urokinase type plasminogen activator receptor and COX-2 for the diagnosis of colorectal cancer. PLoS One 2013;8(01): e51810

104 Illemann M, Laerum OD, Hasselby JP, et al; Danish Study Group on Early Detection of Colorectal Cancer. Urokinase-type plasminogen activator receptor (UPAR) on tumor-associated macrophages is a marker of poor prognosis in colorectal cancer. Cancer Med 2014;3(04):855-864

105 Ahn SB, Chan C, Dent OF, et al. Epithelial and stromal cell urokinase plasminogen activator receptor expression differentially correlates with survival in rectal cancer stages B and C patients. PLoS One 2015;10(02):e0117786

106 Huang W-S, Chin C-C, Chen C-N, et al. Stromal cell-derived factor$1 / C X C$ receptor 4 and $\beta 1$ integrin interaction regulates urokinase-type plasminogen activator expression in human colorectal cancer cells. J Cell Physiol 2012;227(03):1114-1122

107 Liu X, Qiu F, Liu Z, et al. Urokinase-type plasminogen activator receptor regulates apoptotic sensitivity of colon cancer HCT116 cell line to TRAIL via JNK-p53 pathway. Apoptosis 2014;19(10): 1532-1544

108 Jin H, Li XJ, Park MH, Kim SM. FOXM1-mediated downregulation of uPA and MMP9 by 3,3'-diindolylmethane inhibits migration and invasion of human colorectal cancer cells. Oncol Rep 2015; 33(06):3171-3177

109 Van Buren G II, Gray MJ, Dallas NA, et al. Targeting the urokinase plasminogen activator receptor with a monoclonal antibody impairs the growth of human colorectal cancer in the liver. Cancer 2009;115(14):3360-3368

110 Lugli A, Karamitopoulou E, Zlobec I. Tumour budding: a promising parameter in colorectal cancer. Br J Cancer 2012;106(11): 1713-1717

111 Märkl B, Renk I, Oruzio DV, et al. Tumour budding, uPA and PAI-1 are associated with aggressive behaviour in colon cancer. J Surg Oncol 2010;102(03):235-241

112 Märkl B, Hardt J, Franz S, et al. Tumor budding, uPA, and PAI-1 in colorectal cancer: update of a prospective study. Gastroenterol Res Pract 2017;2017:6504960

113 Kim MH, Park JS, Chang HJ, et al. Lysophosphatidic acid promotes cell invasion by up-regulating the urokinase-type plasminogen activator receptor in human gastric cancer cells. J Cell Biochem 2008;104(03):1102-1112

114 Khoi PN, Xia Y, Lian S, et al. Cadmium induces urokinase-type plasminogen activator receptor expression and the cell invasiveness of human gastric cancer cells via the ERK-1/2, NF-KB, and AP-1 signaling pathways. Int J Oncol 2014;45(04): 1760-1768

115 Lian S, Xia Y, Ung TT, et al. Prostaglandin $E_{2}$ stimulates urokinasetype plasminogen activator receptor via EP2 receptor-dependent signaling pathways in human AGS gastric cancer cells. Mol Carcinog 2017;56(02):664-680

116 Pan G, Zhu Z, Huang J, et al. Semaphorin 5A promotes gastric cancer invasion/metastasis via urokinase-type plasminogen activator/phosphoinositide 3-kinase/protein kinase B. Dig Dis Sci 2013;58(08):2197-2204

117 Alpízar-Alpízar W, Christensen IJ, Santoni-Rugiu E, et al. Urokinase plasminogen activator receptor on invasive cancer cells: a prognostic factor in distal gastric adenocarcinoma. Int J Cancer 2012;131(04):E329-E336

118 Ding Y, Zhang H, Zhong M, et al. Clinical significance of the uPA system in gastric cancer with peritoneal metastasis. Eur J Med Res 2013;18:28

119 Ding Y, Zhang H, Lu A, et al. Effect of urokinase-type plasminogen activator system in gastric cancer with peritoneal metastasis. Oncol Lett 2016;11(06):4208-4216

120 Yang XW, Gao F, Chen YJ, Teng FM. The clinical study of urokinase-type plasminogen activator and vascular endothelial growth factor in gastric cancer. Cell Biochem Biophys 2015;72 (03):649-652

121 Tang Z, Sheng H, Zheng X, et al. Upregulation of circulating cytokeratin 20, urokinase plasminogen activator and C-reactive protein is associated with poor prognosis in gastric cancer. Mol Clin Oncol 2015;3(06):1213-1220

122 Tian B, Chen X, Zhang $\mathrm{H}$, et al. Urokinase plasminogen activator secreted by cancer-associated fibroblasts induces tumor progression via PI3K/AKT and ERK signaling in esophageal squamous cell carcinoma. Oncotarget 2017;8(26):42300-42313

$123 \mathrm{Li} \mathrm{H}$, Chen C. Quercetin has antimetastatic effects on gastric cancer cells via the interruption of uPA/uPAR function by modulating NF-kb, PKC- $\delta$, ERK1/2, and AMPK $\alpha$. Integr Cancer Ther 2018;17(02):511-523

$124 \mathrm{Li} \mathrm{T}$, Jiang S. Effect of bFGF on invasion of ovarian cancer cells through the regulation of Ets- 1 and urokinase-type plasminogen activator. Pharm Biol 2010;48(02):161-165

125 Kenny HA, Leonhardt P, Ladanyi A, et al. Targeting the urokinase plasminogen activator receptor inhibits ovarian cancer metastasis. Clin Cancer Res 2011;17(03):459-471

126 Zhang W, Ling D, Tan J, Zhang J, Li L. Expression of urokinase plasminogen activator and plasminogen activator inhibitor type-1 in ovarian cancer and its clinical significance. Oncol Rep 2013;29 (02):637-645

127 Ghasemi A, Hashemy SI, Aghaei M, Panjehpour M. RhoA/ROCK pathway mediates leptin-induced uPA expression to promote cell invasion in ovarian cancer cells. Cell Signal 2017;32:104-114

128 Henic E, Borgfeldt C, Christensen IJ, Casslén B, Høyer-Hansen G. Cleaved forms of the urokinase plasminogen activator receptor in plasma have diagnostic potential and predict postoperative survival in patients with ovarian cancer. Clin Cancer Res 2008;14 (18):5785-5793

129 Kotzsch M, Dorn J, Doetzer K, et al. mRNA expression levels of the biological factors uPAR, uPAR-del4/5, and rab31, displaying prognostic value in breast cancer, are not clinically relevant in advanced ovarian cancer. Biol Chem 2011;392(11):1047-1051

130 Wang L, Madigan MC, Chen $\mathrm{H}$, et al. Expression of urokinase plasminogen activator and its receptor in advanced epithelial ovarian cancer patients. Gynecol Oncol 2009;114(02):265-272

131 Chen H, Hao J, Wang L, Li Y. Coexpression of invasive markers (uPA, CD44) and multiple drug-resistance proteins (MDR1, MRP2) is correlated with epithelial ovarian cancer progression. Br J Cancer 2009;101(03):432-440

132 Almasi CE, Høyer-Hansen G, Christensen IJ, Pappot H. Prognostic significance of urokinase plasminogen activator receptor and its cleaved forms in blood from patients with non-small cell lung cancer. APMIS 2009;117(10):755-761

133 Almasi CE, Christensen IJ, Høyer-Hansen G, et al. Urokinase receptor forms in serum from non-small cell lung cancer patients: relation to prognosis. Lung Cancer 2011;74(03):510-515

134 Almasi CE, Drivsholm L, Pappot H, Høyer-Hansen G, Christensen IJ. The liberated domain I of urokinase plasminogen activator receptor-a new tumour marker in small cell lung cancer. APMIS 2013;121(03):189-196

135 Lee SB, Ho J-N, Yoon SH, Kang GY, Hwang S-G, Um H-D. Peroxiredoxin 6 promotes lung cancer cell invasion by inducing urokinase-type plasminogen activator via p38 kinase, phosphoinositide 3-kinase, and Akt. Mol Cells 2009;28(06):583-588

136 Toupance S, Brassart B, Rabenoelina F, et al. Elastin-derived peptides increase invasive capacities of lung cancer cells by post-transcriptional regulation of MMP-2 and uPA. Clin Exp Metastasis 2012;29(05):511-522

137 Provost JJ, Rastedt D, Canine J, et al. Urokinase plasminogen activator receptor induced non-small cell lung cancer invasion and metastasis requires NHE1 transporter expression and transport activity. Cell Oncol (Dordr) 2012;35(02):95-110

138 Shih C-M, Kuo W-H, Lin C-W, et al. Association of polymorphisms in the genes of the urokinase plasminogen activation system 
with susceptibility to and severity of non-small cell lung cancer Clin Chim Acta 2011;412(1-2):194-198

139 Büchler P, Reber HA, Tomlinson JS, et al. Transcriptional regulation of urokinase-type plasminogen activator receptor by hypoxia-inducible factor 1 is crucial for invasion of pancreatic and liver cancer. Neoplasia 2009;11(02):196-206

140 Gorantla B, Asuthkar S, Rao JS, Patel J, Gondi CS. Suppression of the uPAR-uPA system retards angiogenesis, invasion, and in vivo tumor development in pancreatic cancer cells. Mol Cancer Res 2011;9(04):377-389

141 Asuthkar S, Stepanova V, Lebedeva T, et al. Multifunctional roles of urokinase plasminogen activator ( $\mathrm{UPA}$ ) in cancer stemness and chemoresistance of pancreatic cancer. Mol Biol Cell 2013;24(17): 2620-2632

142 Fontanil T, Mohamedi Y, Esteban MM, Obaya AJ, Cal S. Polyserase1/TMPRSS9 induces pro-tumor effects in pancreatic cancer cells by activation of pro-uPA. Oncol Rep 2014;31(06):2792-2796

143 He X, Zheng Z, Li J, et al. DJ-1 promotes invasion and metastasis of pancreatic cancer cells by activating SRC/ERK/uPA. Carcinogenesis 2012;33(03):555-562

144 de Geus SW, Baart VM, Boonstra MC, et al. Prognostic impact of urokinase plasminogen activator receptor expression in pancreatic cancer: malignant versus stromal cells. Biomark Insights 2017; 12:1177271917715443 